\title{
Effects of Anion Coordination on the Fluorescence of a Photo-induced Electron Transfer (PET) Sensor Complexed with Metal Ions.
}

Joseph W. Nugent, ${ }^{\dagger}$ Hyunjung Lee ${ }^{\dagger}$, Joseph H. Reibenspies, ${ }^{\S}$ Hee-Seung Lee, ${ }^{+*}$ and Robert D. Hancock $^{+*}$

Department of Chemistry and Biochemistry, University of North Carolina

Wilmington, Wilmington, North Carolina 28403,USA, and Department of Chemistry,Texas A\&M University, College Station, Texas 77843, USA. 


\begin{abstract}
Whether $\pi$ contacts between the fluorophore of the photoinduced electron transfer (PET) sensor adpa ((N-(9-anthracenylmethyl)-N-(2-pyridinylmethyl)-2-pyridinemethanamine) and complexed metal ions or coordinated halide ions control the fluorescence intensity of adpa is further investigated via fluorescence, absorbance and density functional theory (DFT) studies. Three metal-adpa complexes were studied and the crystal structures of $\left[\mathrm{Cd}(\operatorname{adpa}) \mathrm{I}_{2}\right](\mathbf{1}),\left[\mathrm{Hg}(\operatorname{adpa}) \mathrm{I}_{2}\right]$
\end{abstract} (2), $\left[\mathrm{Zn}(\operatorname{adpa}) \mathrm{Cl}_{2}\right]\left(\mathrm{H}_{2} \mathrm{O}\right)_{2}(3)$ and $\left[\mathrm{Cd}(\operatorname{adpa}) \mathrm{S}_{2} \mathrm{O}_{3}\right]_{2}(4)$ are reported. Unlike $\mathrm{Cl}^{-}, \mathrm{Br}^{-}, \mathrm{SCN}^{-}$and $\mathrm{S}_{2} \mathrm{O}_{3}{ }^{2-}$, which cause an increase in fluorescence intensity upon binding to $\mathrm{Cd}^{\mathrm{II}}$ (adpa) due to the disruption of metal-fluorophore $\pi$ contacts, coordination of $\mathrm{I}^{-}$to the $\mathrm{Cd}^{\mathrm{II}}$ (adpa) complex strongly decreases fluorescence intensity. The same trend was found with the addition of $\mathrm{I}^{-}$to the $\mathrm{Hg}^{\mathrm{II}}$ (adpa) and $\mathrm{Zn}^{\mathrm{II}}$ (adpa) complexes. However, the causes of fluorescence quenching associated with three metal complexes are not necessarily the same. The structure of $\mathbf{3}$ shows that the anthracenyl fluorophore does not form a $\pi$ contact with the $\mathrm{Zn}$, relating to the strong $\mathrm{CHEF}$ (chelation enhanced fluorescence) effect $\mathrm{Zn}^{\mathrm{II}}$ shows with adpa. The absorbance study suggests that the fluorescence quenching of the $\mathrm{Zn}^{\mathrm{II}}$ (adpa) complex with $\mathrm{I}^{-}$addition is due to collisional quenching. Fluorescence quenching in the $\mathrm{Hg}(\mathrm{adpa}) \mathrm{I}_{2}$ complex is attributed to the long $\mathrm{Hg}-\mathrm{N}$ bond of $2.788 \AA$ to the central $\mathrm{N}$ donor of the adpa in $\mathbf{2}$, which causes quenching by a PET effect from the weakly coordinated $\mathrm{N}$ donor. The quenching mechanism associated with the $\mathrm{Cd}^{\mathrm{II}}($ adpa $) \mathrm{I}_{2}$ complex seems to be more subtle. Structure $\mathbf{1}$ shows the nearest $\mathrm{Cd} \cdots \mathrm{C}$ distance to the anthracenyl fluorophore of adpa of $3.554 \AA$, where such long distances are usually associated with increases in fluorescence intensity, rather than quenching. Density functional theory (DFT) studies showed that there is structural change in the excited state of the $\mathrm{Cd}^{\mathrm{II}}(\mathrm{adpa}) \mathrm{I}_{2}$ complex, which triggers a reordering of frontier molecular orbitals. This leads to the involvement of charge transfer from the fluorophore to the iodine in the $\mathrm{S}_{1} \rightarrow \mathrm{S}_{0}$ transition, which is forbidden. 


\section{INTRODUCTION.}

A major aspect of modern chemistry is the study of relatively weak interactions, such as those involving $\pi$ systems of aromatic groups in chemical and biological processes [1-10]. The $\pi$ interactions of aromatics can be with cations [1-4], or with $\mathrm{H}$ atoms, including those on carbohydrates [5], with anions [6], or with halogens that are typically part of organic molecules [7], and also involve $\pi$ stacking of aromatic systems with each other [4,8-10]. In previous papers we have explored the possible role of $\pi$ contacts between the aromatic fluorophores of fluorescent sensors and the metal ions complexed by the sensor, in quenching the fluorescence of such sensors [11-15]. The idea that $\pi$ contacts might quench fluorescence was first suggested by Czarnik et al. [16,17], and was more extensively investigated by the present authors with the adpa fluorescent sensor (see Figure 1 for the abbreviations of molecules discussed in this paper) [11-15]. The existence of $\pi$ contacts between heavy diamagnetic metal ions and the aromatic fluorophores of sensors was demonstrated crystallographically [11-13,15]. The hypothesis suggests that such $\pi$ contacts are largely responsible for quenching the fluorescence of photoinduced electron transfer (PET) sensors for metal ions with tethered fluorophores.

The structures of adpa complexes, together with DFT calculations, and an analysis of $\pi$ contacted structures with metal ions found in the CSD [18], have suggested an order of increasing ability to form $\pi$ contacts in solution, which is $\mathrm{Ni}^{\mathrm{II}} \sim \mathrm{Zn}^{\mathrm{II}}<<\mathrm{Cd}^{\mathrm{II}}<\mathrm{Pb}^{\mathrm{II}}<\mathrm{Hg}^{\mathrm{II}}<\mathrm{Pd}^{\mathrm{II}} \sim$

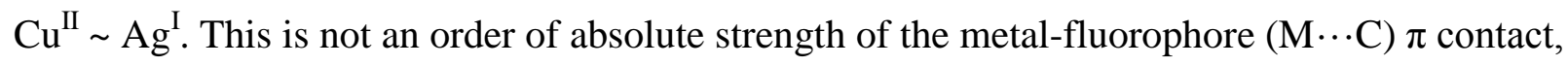
but of the ease of formation of a $\pi$ contact including any necessary displacement of coordinated solvent molecules from the metal ion. One thus finds that more easily desolvated monovalent metal ions such as $\mathrm{Ag}^{\mathrm{I}}$ and $\mathrm{Tl}^{\mathrm{I}}$, and possibly also alkali metal ions [1], are prone to form $\pi$ contacts in solution. Other metal ions that readily form $\pi$ contacts in solution are: square planar 
or tetragonally distorted metal ions such as $\mathrm{Pd}^{\mathrm{II}}$ and $\mathrm{Cu}^{\mathrm{II}}$, that are easily desolvated on their axial coordination sites: metal ions with lone pairs, such as $\mathrm{Pb}^{\mathrm{II}}$ that are easily desolvated near the lone pair: heavy $\mathrm{d}^{10}$ metal ions such as $\mathrm{Hg}^{\mathrm{II}}$, which also applies to $\mathrm{Ag}^{\mathrm{I}}$, that form quasi-linear complexes that are only weakly solvated on the remaining coordination sites.

The $\pi$ contact model of fluorescence quenching in adpa type PET sensors suggests [11-15] that a second ligand might bind to the metal-adpa complex, and weaken or disrupt the $\pi$ contact

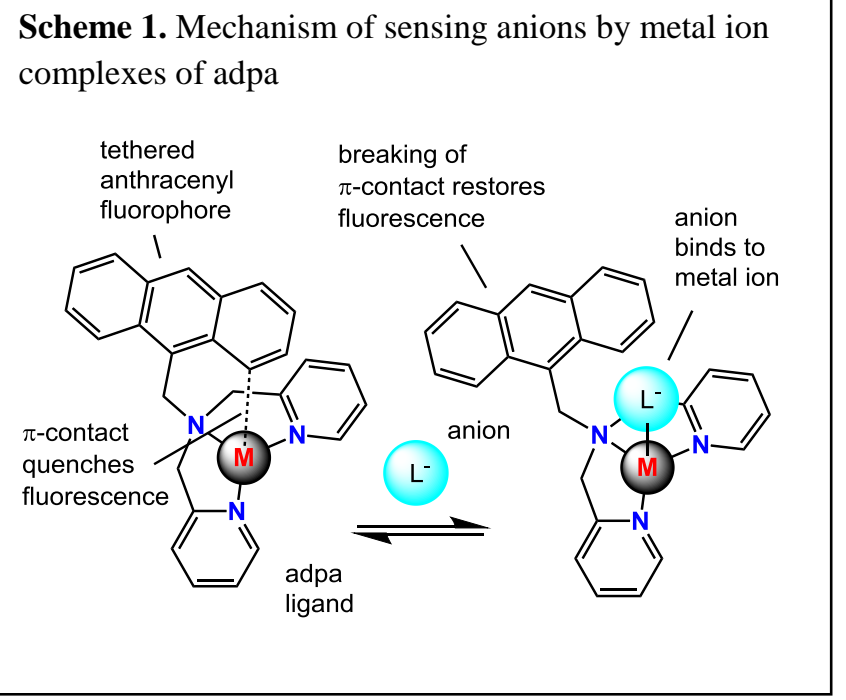

Scheme 1. Mechanism of sensing anions by metal ion complexes of adpa

uorescence

that is quenching fluorescence, and

increase the fluorescence intensity (Scheme

1). Thus, we can use the $\pi$ contact model as

a basis for the development of novel "turnon" anion sensors. We first confirmed this idea with the $\mathrm{Cd}^{\mathrm{II}}$ adpa complex $[12,13]$. $\mathrm{Cd}^{\mathrm{II}}$ is at the weaker end of the series in $\pi$ contacting ability mentioned above and the fluorescence intensity of the $\mathrm{Cd}^{\mathrm{II}}$ adpa

complex decreases only about $25 \%$ from that of the $\mathrm{Zn}^{\mathrm{II}}$ adpa complex with no $\pi$ contact.

Nevertheless, it was found that there is an increase in fluorescence intensity when $\mathrm{Cl}^{-}, \mathrm{Br}^{-}, \mathrm{SCN}^{-}$ and $\mathrm{S}_{2} \mathrm{O}_{3}{ }^{2-}$ bind to the $\mathrm{Cd}^{\mathrm{II}}$ adpa complex $[12,13]$. Disruption of $\pi$ contacts through the binding of $\mathrm{Cl}^{-}$and $\mathrm{Br}^{-}$, however, did not lead to an increase in fluorescence intensity for the $\mathrm{Hg}^{\mathrm{II}}$ adpa complex even though $\mathrm{Hg}^{\mathrm{II}}$ has a stronger tendency to form $\pi$ contacts. We believe that this is due to the distortion of the coordination geometry around heavy $\mathrm{d}^{10}$ metal ions such as $\mathrm{Hg}^{\mathrm{II}}$ [11-15]. As is typical for heavy $\mathrm{d}^{10}$ ions, a quasi-linear structure may be produced [19-21], with, in the case of adpa, short $\mathrm{Hg}-\mathrm{N}$ bonds to the more covalently binding $\mathrm{sp}^{2}$ hybridized $\mathrm{N}$ donors of the 
two pyridyl groups, which are placed at roughly $180^{\circ}$ to each other [11-15]. Long $\mathrm{Hg}-\mathrm{N}$ bonds to the remaining $\mathrm{sp}^{3}$ hybridized $\mathrm{N}$ donor atoms are found, which are placed at roughly right angles to the more covalently binding donors in the favored linear sites. This long $\mathrm{Hg}-\mathrm{N}$ bond means that even when the $\mathrm{Hg} \cdots \mathrm{C} \pi$ contact that is thought to quench the fluorescence of the complex is disrupted by coordination of a halide, the $\mathrm{N}$ donor from the long $\mathrm{Hg}-\mathrm{N}$ bond still produces a PET effect, and no significant increase in fluorescence intensity is observed.

To further investigate the role of $\pi$ contacts in quenching fluorescence intensity, as well as the importance of coordination geometry of heavy $\mathrm{d}^{10}$ elements in PET, we performed crystallographic, spectroscopic and computational studies of $\mathrm{Zn}^{\mathrm{II}}$ adpa, $\mathrm{Cd}^{\mathrm{II}}$ adpa and $\mathrm{Hg}^{\mathrm{II}}$ adpa complexes coordinated with anions $\left(\mathrm{SCN}^{-}, \mathrm{Cl}^{-}\right.$, and $\left.\mathrm{I}^{-}\right)$. One of the interesting findings in the fluorescence studies of these complexes is the effect of I' coordination. When the Cd ${ }^{\mathrm{II}}$ adpa complex is coordinated by $\mathrm{SCN}^{-}$, an increase in fluorescence intensity was observed due to the disruption of the $\pi$ contact as with other anions reported in our previous studies [12-13]. In contrast, iodide produces a so-far unique effect on the fluorescence of the $\mathrm{Cd}^{\mathrm{II}}$ adpa complex, which is that it strongly quenches it. A similar effect was found for the $\mathrm{Zn}^{\mathrm{II}}$ adpa complex. Thus, important questions arise: what makes iodide anion behave so differently from any other anions investigated so far, and what is the quenching mechanism associated with iodide binding? One possibility is that iodide quenches fluorescence via a $\pi$ contact with the fluorophore. Iodide is a larger and softer anion than chloride. Thus, it might form a $\pi$ contact with the anthracenyl group, which subsequently quenches fluorescence. However, one has to consider other possibilities as well, such as that the iodide ion quenches the fluorescence of the $\mathrm{Cd}^{\mathrm{II}}$ adpa complex by collisional quenching. It is also not immediately clear whether the fluorescence quenching due to iodide coordination occurs via the same mechanism in the $\mathrm{Cd}^{\mathrm{II}}$ adpa and $\mathrm{Zn}$ adpa complexes. 
In this paper, we report the results of our spectroscopic and computational studies to answer the questions raised above regarding the formation of $\pi$ contacts and anion coordination, $\mathrm{I}^{-}$anion in particular, together with crystallographic studies of $\left[\mathrm{Cd}^{\mathrm{II}}(\operatorname{adpa}) \mathrm{I}_{2}\right],\left[\mathrm{Hg}^{\mathrm{II}}(\mathrm{adpa}) \mathrm{I}_{2}\right]$ and $\left[\mathrm{Zn}^{\mathrm{II}}(\mathrm{adpa}) \mathrm{Cl}_{2}\right]$. As for the spectroscopic studies, we investigated the effect of $\pi$ contacts on the absorption spectra as well as the fluorescence spectra. The motivation behind the absorbance study is that if the formation of $\pi$ contacts affects the fluorescence intensity so strongly, such $\pi$ contacts should also affect the absorption bands due to $\pi \rightarrow \pi^{*}$ transitions in the fluorophore in such a way that reflects the presence of $\pi$ contacts, and the strength of the $\pi$ contact. As will be shown in this work, investigation of the effect of binding of metal ions to adpa on its absorbance spectrum provides valuable insights into the importance of $\pi$ contacts. Complimentary to the spectroscopic study, we also performed density functional theory (DFT) and time-dependent DFT (TDDFT) calculations to better understand the physical origin of the strong quenching of fluorescence by iodide anion. Our DFT studies showed that there is a subtle difference in electronic structures between the $\mathrm{Cd}^{\mathrm{II}}($ adpa $) \mathrm{Cl}_{2}$ complex and $\mathrm{Cd}^{\mathrm{II}}($ adpa $) \mathrm{I}_{2}$ complex, leading to the observed difference between them in quenching fluorescence.

\section{EXPERIMENTAL AND COMPUTATION}

Materials: The ligand adpa was synthesized following a literature method [22]. The metal salts $\mathrm{CdI}_{2}, \mathrm{HgI}_{2} . \mathrm{ZnCl}_{2}$, and $\mathrm{Cd}\left(\mathrm{NO}_{3}\right)_{2} \cdot 6 \mathrm{H}_{2} \mathrm{O}$, and metal perchlorates, were obtained from VWR or Strem in $\geq 99 \%$ purity and used as received. All solutions were made up in deionized water (Milli-Q, Waters Corp.) of $>18 \mathrm{M} \Omega . \mathrm{cm}^{-1}$ resistivity, plus HPLC grade methanol from Merck. Elemental analyses: The $\mathrm{C}$ and $\mathrm{N}$ elemental compositions were measured with a $\mathrm{CE}$ Elantech model NC 2100CHN analyzer [23], which offers the advantage that individual crystals can be selected for in-house analysis. 
Synthesis of [Cd(adpa) $\mathbf{I}_{2}$ ] (1): One equivalent of adpa (35.0 mg, $\left.0.09 \mathrm{mmol}\right)$ was dissolved in methanol (3mL) and added to a solution of one equivalent of $\mathrm{Cd}\left(\mathrm{NO}_{3}\right)_{2}(29.8 \mathrm{mg}, 0.09 \mathrm{mmol})$ in methanol $(3 \mathrm{~mL})$ in a $20 \mathrm{~mL}$ sample vial. The vial containing the resulting solution was placed standing upright in a jar capped with a tightly closed lid, containing diethyl ether to a depth of about $5 \mathrm{~mm}$. Diffusion of diethyl ether vapor into the solution resulted in deposition of paleyellow crystals over a period of a few days. Yield: $25.7 \mathrm{mg}$ (39.6\%); IR spectrum: intense bands $\left(\mathrm{cm}^{-1}\right)$ at $3048,2395,1570,1433,1383.0,1050,833,764$; Elemental analysis: C, $42.48 \%$; , $5.39 \%$ (calculated composition for $\mathrm{C}_{27} \mathrm{H}_{23} \mathrm{CdN}_{3} \mathrm{I}_{2}: \mathrm{C}, 42.91 \% ; \mathrm{N}, 5.56 \%$ ).

Synthesis of [Hg(adpa) $\left.\mathbf{I}_{2}\right]$ (2): One equivalent of adpa (35.0 mg, $\left.0.09 \mathrm{mmol}\right)$ was dissolved in $20 \% \mathrm{DMSO} / \mathrm{methanol}(4 \mathrm{~mL})$ and added to a solution of one equivalent of $\mathrm{HgI}_{2}(40.9 \mathrm{mg}, 0.09$ $\mathrm{mmol}$ ) in $20 \% \mathrm{DMSO} / \mathrm{methanol}(4 \mathrm{~mL})$ in a $30 \mathrm{~mL}$ sample vial. The ether diffusion method described for $\mathbf{1}$ above was followed which resulted in deposition of clusters of pale-yellow crystals in a matter of hours. The solution was filtered off under vacuum and the crystals were air-dried. Elemental analysis: C, 38.60\%; N, $5.03 \%$. (calculated composition for $\mathrm{C}_{27} \mathrm{H}_{23} \mathrm{HgI}_{2} \mathrm{~N}_{3}$ : C, 38.43\%; N, 4.98\%).

Synthesis of $\left[\mathbf{Z n}(\mathbf{a d p a}) \mathbf{C l}_{2}\right]\left(\mathbf{H}_{\mathbf{2}} \mathbf{O}\right)_{\mathbf{2}} \mathbf{( 3 )}$ : One equivalent of adpa (35.0 $\left.\mathrm{mg}, 0.09 \mathrm{mmol}\right)$ was dissolved in methanol (4mL) and added to a solution of one equivalent of $\mathrm{ZnCl}_{2}(12.3 \mathrm{mg}, 0.09$ $\mathrm{mmol})$ in methanol $(4 \mathrm{~mL})$ in a $30 \mathrm{~mL}$ sample vial. The ether diffusion method described above for $\mathbf{1}$ was followed which resulted in deposition of needle-like pale-yellow crystals in a matter of minutes. Elemental analysis: C, 57.87\%; N, $7.18 \%$ (calculated composition for $\mathrm{C}_{27} \mathrm{H}_{27} \mathrm{Cl}_{2} \mathrm{~N}_{3} \mathrm{O}_{2} \mathrm{Zn}: \mathrm{C}, 57.72 \%$; N, $7.48 \%$ ).

Synthesis of $\left[\mathbf{C d}(\mathbf{a d p a})\left(\mathbf{S}_{\mathbf{2}} \mathbf{O}_{3}\right)\right]$ (4): One equivalent of adpa $(35.0 \mathrm{mg}, 0.09 \mathrm{mmol})$ was dissolved in methanol (3mL) and added to a solution of one equivalent of $\mathrm{Pb}\left(\mathrm{NO}_{3}\right)_{2}(29.8 \mathrm{mg}, 0.09 \mathrm{mmol})$ 
in methanol (3 mL) in a $20 \mathrm{~mL}$ sample vial. The vial containing the resulting solution was placed standing upright in a jar with a lid, containing diethyl ether to a depth of about $5 \mathrm{~mm}$, and the jar was tightly closed. Diffusion of diethyl ether vapor into the solution resulted in deposition of pale-yellow crystals over a period of a few days. Yield, $25.7 \mathrm{mg}=39.6 \%$. IR spectrum, more intense bands $\left(\mathrm{cm}^{-1}\right)$ : 3048, 2395, 1570, 1433, 1383.0, 1050, 833, 764. Elemental analysis: calcd. for $\mathrm{C}_{27} \mathrm{H}_{23} \mathrm{CdN}_{3} \mathrm{~S}_{2} \mathrm{O}_{3}$ : C, $52.81 \% ; \mathrm{N}, 6.84 \%$. Found: C, $52.44 \% ; \mathrm{N}, 6.35 \%$.

Molecular structure determination. A Bruker APEX-II CCD X-ray (three-circle) diffractometer was employed for crystal screening, unit cell determination, and data collection. The structures were solved by direct methods, and refined to convergence [24]. Details of the structure determination are given in Table 1, and crystal coordinates and details of the structure determination of 1-4 have been deposited with the CSD (Cambridge Structural Database) [18]. Fluorescence measurements: Excitation-emission matrix (EEM) fluorescence properties were determined on a Jobin Yvon SPEX Fluoromax-3 scanning fluorometer equipped with a $150 \mathrm{~W}$ Xe arc lamp and a R928P detector. The instrument was configured to collect the signal in ratio mode with dark offset using $5 \mathrm{~nm}$ band-passes on both the excitation and emission monochromators. The EEMs were created by concatenating emission spectra measured every 5 $\mathrm{nm}$ from 250 to $500 \mathrm{~nm}$ at 51 separate excitation wavelengths. Scans were corrected for instrument configuration using factory supplied correction factors. The fluorescence of the adpa solutions was recorded in 50\% $\mathrm{MeOH} /$ water, with titrations occurring in an external cell with $\mathrm{N}_{2}$ bubbled through the cell to exclude $\mathrm{O}_{2}$.

Absorbance spectra. UV-Visible spectra were recorded using a Varian 300 Cary 1E UV-Visible Spectrophotometer controlled by Cary Win UV Scan Application version 02.00(5) software. A VWR sympHony ${ }^{\mathrm{TM}}$ SR60IC $\mathrm{pH}$ meter with a VWR sympHony ${ }^{\mathrm{TM}}$ gel epoxy semi-micro 
combination $\mathrm{pH}$ electrode was used for all $\mathrm{pH}$ readings, which were made in the external titration cell, with $\mathrm{N}_{2}$ bubbled through the cell to exclude $\mathrm{CO}_{2}$. The absorbance spectra of the adpa solutions were recorded in 50\% $\mathrm{MeOH} /$ water.

Density functional theory (DFT) calculations: All DFT/TDDFT calculations reported in this work were carried out with the ab initio quantum chemistry package GAMESS [25]. Ground state geometry optimizations of the $\left[\mathrm{Cd}^{\mathrm{II}}(\operatorname{adpa}) \mathrm{Cl}_{2}\right]$ and $\left[\mathrm{Cd}^{\mathrm{II}}(\operatorname{adpa}) \mathrm{I}_{2}\right]$ complexes were performed within the framework of Kohn-Sham DFT with B3LYP exchange-correlation (XC) functional $[26,27]$. The $\mathrm{SV}(\mathrm{P})$ basis set [28] was used for the main group elements, whereas the Lanl2DZ [29-51] effective core potential was employed for the metal ions. Optimized excited state geometries were obtained via time-dependent DFT calculations with the same XC functional and the basis set as with the ground state calculations. The oscillator strengths for the $\mathrm{S}_{1} \rightarrow \mathrm{S}_{0}$ transition (fluorescence) were calculated with the optimized excited state geometries. The same computational approach was adopted in our previous study of the $\mathrm{Hg}^{\mathrm{II}}$ (adpa) complex [14].

For geometry optimizations of both ground and excited states, we considered various starting geometries. Since the $\mathrm{Cd}^{\mathrm{II}}(\mathrm{adpa})$ complex can exist in two different forms in solution [12] with and without $\pi$ contacts, we considered both as starting geometries. According to the Xray structures [12], two pyridyl groups in the non- $\pi$-contacted $\mathrm{Cd}^{\mathrm{II}}(\operatorname{adpa}) \mathrm{Cl}_{2}$ complex are almost at right angle, but that is not the case in the $\mathrm{Zn}^{\mathrm{II}}(\mathrm{adpa}) \mathrm{Cl}_{2}$ complex, where the two pyridyl groups lie roughly in the same plane. Thus, we considered both possibilities for the geometry optimizations. The typical coordination number of $\mathrm{Cd}^{\mathrm{II}}$ complex is 6 and the anthracenyl group is considered to occupy the $6^{\text {th }}$ coordination site in the $\pi$-contacted complexes. In the case of non- $\pi$ contacted model, we placed a water molecule at the $6^{\text {th }}$ coordination site. All DFT/TDDFT 
calculations were performed in an aqueous solution environment using the polarizable continuum model (PCM) as implemented in GAMESS.

\section{RESULTS AND DISCUSSION}

Fluorescence spectra of $\mathbf{C d}^{\text {II }}(\mathbf{a d p a})$ : In Figure 2 is seen the change in fluorescence intensity of the $\mathrm{Cd}^{\mathrm{II}}(\mathrm{adpa})$ complex as a function of $\mathrm{SCN}^{-}$concentration, which is typical of changes produced by coordination of more covalently binding anions to the $\mathrm{Cd}^{\mathrm{II}}$ such as $\mathrm{Cl}^{-}, \mathrm{Br}^{-}$, and $\mathrm{S}_{2} \mathrm{O}_{3}{ }^{-}[12,13]$. An exception to this trend is iodide anion. As seen in Figure 3, iodide strongly quenches the fluorescence of the $\mathrm{Cd}^{\mathrm{II}}(\mathrm{adpa})$ complex. The decrease in fluorescence intensity is also accompanied by a shift in peak position and a change in overall peak shape. The change in fluorescence intensity of the $\mathrm{Cd}^{\mathrm{II}}$ (adpa) complex at several wavelengths as a function of $\mathrm{I}^{-}$ concentration (Figure 4) produces a doubly inflected curve of intensity versus $\log \left[\mathrm{I}^{-}\right]$, which suggests successive binding of two $\mathrm{I}^{-}$anions to the $\mathrm{Cd}^{\mathrm{II}}$. The curves of fluorescence intensity vs. $\log \left[\mathrm{I}^{-}\right]$in Figure 4 were fitted to yield $\log \mathrm{K}_{1}=4.56$ and $\log \mathrm{K}_{2}=2.51$ for binding of iodides to the $\mathrm{Cd}^{\mathrm{II}}$ (adpa) complex using Excel [32]. Thus, a structural study of the $\mathrm{Cd}^{\mathrm{II}}(\mathrm{adpa}) \mathrm{I}_{2}$ complex might show possible $\mathrm{I} \cdots \mathrm{C}$ contacts between the iodide ions coordinated to $\mathrm{Cd}$, and the $\pi$ system of the fluorophore of adpa, which might be interpreted as causing the quenching of the fluorescence of the $\mathrm{Cd}^{\mathrm{II}}$ (adpa) complex brought about by coordination of $\mathrm{I}^{-}$ions.

We also observed that the fluorescence spectrum of the $\mathrm{Zn}^{\mathrm{II}}$ (adpa) complex shows fairly strong quenching by $\mathrm{I}^{-}$(Figure 5). However, quenching occurs at a considerably higher $\mathrm{I}^{-}$ concentration than does the fluorescence quenching of the $\mathrm{Cd}^{\mathrm{II}}$ (adpa) complex (Figure 3 ), and is not accompanied by any shifts in peak position or changes in appearance of the fluorescence spectra as $\left[\mathrm{I}^{-}\right]$increases. Therefore, it is not entirely clear whether the quenching mechanisms 
associated with I' binding are the same for both complexes. In the following, we will investigate the possible quenching mechanisms associated with I' binding through crystallographic, absorbance and density functional theory (DFT) studies.

Structure of [Cd(adpa) $\left.\mathbf{I}_{2}\right]$ (1): The structure of $\mathbf{1}$ is shown in Figure 6. The Cd ${ }^{\mathrm{II}}$ is 6-coordinate if one includes the long $\mathrm{Cd} \cdots \mathrm{C}$ contact of $3.554 \AA$, noting that the sum of the v.d. Waals radii of $\mathrm{C}$ and $\mathrm{Cd}$ is $3.28 \AA$ : the criterion for the presence of a $\pi$ contact is that the $\mathrm{Cd} \cdots \mathrm{C}$ distance should be less than the latter. The adpa is coordinated in a mer (meridional) fashion, with the Cd$\mathrm{N}$ bonds to the pyridyl $\mathrm{N}$ donors being $2.313 \AA$ and $2.335 \AA$. The $\mathrm{Cd}-\mathrm{N}$ bond involving the central $\mathrm{N}$ donor is rather long at $2.511 \AA$, which one assumes arises from a type of structural trans effect exerted by the very covalently binding iodides. The Cd-I bonds appear quite normal in length at 2.741 and $2.802 \AA$.

The point of interest in structure $\mathbf{1}$ is whether it provides any insights into why binding of iodides to the $\mathrm{Cd}^{\mathrm{II}}$ in its adpa complex leads to strong quenching of fluorescence, whereas binding of $\mathrm{Cl}^{-}, \mathrm{Br}^{-}, \mathrm{SCN}^{-}$, and $\mathrm{S}_{2} \mathrm{O}_{3}{ }^{2-}$ leads to enhancement of fluorescence intensity. It would

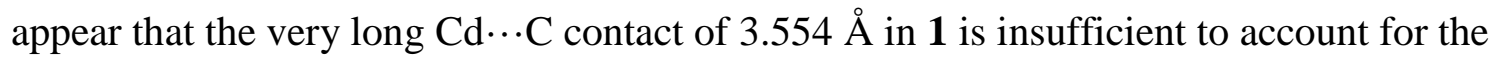
quenching of the fluorescence of the $\mathrm{Cd}^{\mathrm{II}}(\mathrm{adpa})$ complex: other $\mathrm{Cd}^{\mathrm{II}}(\mathrm{adpa})$ complexes with similarly long Cd $\cdots \mathrm{C}$ contacts show no quenching [13]. One possibility is that the coordinated iodides in $\mathbf{1}$ quench fluorescence by forming $\pi$ contacts with the anthracenyl fluorophore of adpa. The shortest contact between an iodide and a $\mathrm{C}$ atom of the fluorophore in $\mathbf{1}$ is $3.727 \AA$, between I(2) and C(17). Iodides, particularly organic iodides, form a large number of $\pi$ contacts with aromatic rings. A search of the CSD yields 505 organic iodides forming $\pi$ contacts with $\mathrm{I} \cdots \mathrm{C}$ distances equal to or less than $3.68 \AA$, the sum of the van der Waals radii [34]. The I...C distance of $3.727 \AA$ would thus appear to be too long to be a $\pi$ contact. Even in the case of this being a $\pi$ 
contact, it would be a rather weak one, being at best slightly larger than the sum of van der Waals radii.

Structure of [Hg(adpa) $\left.\mathbf{I}_{2}\right]$ (2): The structure of $\mathbf{2}$ is seen in Figure 7. The $\mathrm{Hg}^{\mathrm{II}}$ in $\mathbf{2}$ might be described as 5-coordinate if one included the very long $\mathrm{Hg}-\mathrm{N}(2)$ bond of 2.788(3) $\AA$ to the central $\mathrm{sp}^{3}$ hybridized $\mathrm{N}$ of the adpa ligand, which is much longer than the more normal Hg-N(1)

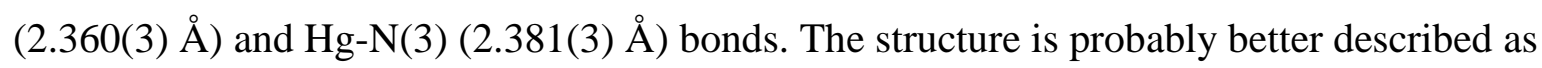
having a 4-coordinate rather distorted tetrahedral geometry involving the two $\mathrm{sp}^{2}$ hybridized $\mathrm{N}$ donors of adpa and the two iodides. The bond angles around the $\mathrm{Hg}^{\mathrm{II}}$ in the approximate tetrahedron are: I(1)-Hg-I(2), 122.282(9) ${ }^{\circ}$; I(1)-Hg-N(1), 104.01(7) ${ }^{\circ}$; I(1)-Hg-N(3), 101.60(7) ${ }^{\circ}$; $\mathrm{I}(2)-\mathrm{Hg}-\mathrm{N}(1), 100.11(7)^{\circ} ; \mathrm{I}(2)-\mathrm{Hg}-\mathrm{N}(3), 103.62(7)^{\circ} ; \mathrm{N}(1)-\mathrm{Hg}-\mathrm{N}(3), 127.45(10)^{\circ}$.There is no sign of a $\pi$ contact between the $\mathrm{Hg}$ and the anthracenyl fluorophore. The shortest $\mathrm{Hg} \cdots \mathrm{C}$ distance to the fluorophore is $3.791 \AA$, well beyond the sum of the van der Waals radii of $\mathrm{Hg}$ and $\mathrm{C}$ of 3.25 $\AA$ [34]. Similarly, the shortest I...C distance to the fluorophore is $4.122 \AA$, leaving no room to suggest that a $\pi$ contact is present $(\mathrm{I} \cdots \mathrm{C}<3.80 \AA)$.

The structure of $\mathbf{2}$ is dominated by the tendency of $\mathrm{Hg}^{\mathrm{II}}$ to adopt a coordination geometry with short bonds to the more covalently binding donor atoms present, and long bonds to any remaining more ionically binding donor atoms [19-21]. This most frequently results in approximately linear coordination geometry involving the two most covalently binding donor atoms present: this is observed with $\left[\mathrm{Hg}(\operatorname{adpa})(\mu-\mathrm{Cl})_{2} \mathrm{HgCl}_{2}\right]$, where the first $\mathrm{Hg}$ forms short $\mathrm{Hg}$ $\mathrm{N}$ bonds to the two $\mathrm{sp}^{2}$ hybridized $\mathrm{N}$ donors from the pyridyl groups of the adpa ligand, and long bonds $(\sim 2.6 \AA)$ to the two bridging chlorides and to the $\mathrm{sp}^{3}$ hybridized central $\mathrm{N}$ of the adpa [11]. In contrast, in $\mathbf{2}$ as noted above, the two covalent $\mathrm{Hg}$-I bonds and two covalent $\mathrm{sp}^{2}$ hybridized $\mathrm{N}$ donors from the pyridyl groups of adpa combine to form an approximately 
tetrahedral structure with a very long $\mathrm{Hg}-\mathrm{N}$ bond to the $\mathrm{sp}^{3}$ hybridized central $\mathrm{N}$ of adpa. The $\mathrm{Hg}$-I bonds in 2 at 2.716 and $2.744 \AA$ fall close to the Hg-I bonds of $2.788 \pm 0.056 \AA$ found for 47 structures in the CSD containing tetrahedral $\left[\mathrm{HgI}_{4}\right]^{2-}$ anions. When $\mathrm{Hg}-\mathrm{I}$ bonds are excluded from the favored coordination sites on $\mathrm{Hg}$, they can be very long, as in the case of a structure with a quasi linear I-Hg-I group and $\mathrm{Hg}$-I bonds of $2.61 \AA$, where the four $\mathrm{Hg}-\mathrm{I}$ bonds at right angles to this may be as long as $3.50 \AA$ [35].

The drive of the $\mathrm{Hg}^{\mathrm{II}}$ in $\mathbf{2}$ to form a tetrahedral structure involving the two $\mathrm{N}$ donors from the pyridyl groups of adpa, and the two iodides, results in a very long Hg-N bond (2.788(3) $\AA$ ) to the central $\mathrm{N}$ donor of adpa, which pushes the $\mathrm{Hg}^{\mathrm{II}}$ away from the fluorophore. This means that any possibility of even long $\mathrm{Hg} \cdots \mathrm{C}$ or $\mathrm{I} \cdots \mathrm{C}$ contacts in $\mathbf{2}$ is overcome by the forced large separation of the $\mathrm{Hg}^{\mathrm{II}}$ from the anthracenyl fluorophore. One notes that the lengthening of the $\mathrm{Hg}-\mathrm{N}$ bond to the central $\mathrm{N}$ of adpa becomes more marked as more covalently bound anions are coordinated to $\mathrm{Hg}^{\mathrm{II}}: \mathrm{NO}_{3}{ }^{-}, 2.51 \AA$ (DFT calculation); $\mathrm{Cl}^{-}, 2.603 \AA$; $\mathrm{Br}^{-}, 2.917 \AA$ 政, $2.788 \AA$. At the same time the $\mathrm{Hg} \cdots \mathrm{C}$ contacts with the fluorophore of adpa appear to be affected in the same way: $\mathrm{H}_{2} \mathrm{O}$,

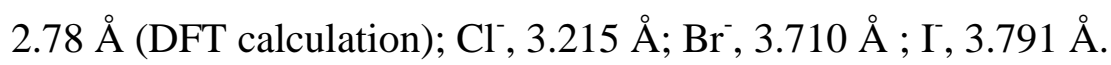

Structure of $\left[\mathbf{Z n}(\mathbf{a d p a}) \mathbf{C l}_{2}\right] .2 \mathbf{H}_{2} \mathbf{O}(3)$ : The structure of $\mathbf{3}$ is seen in Figure 8 . The $\mathrm{Zn}$ in $\mathbf{3}$ is 5-coordinate, with Zn-N bonds of 2.117(3) and 2.116(3) $\AA$ to the two sp ${ }^{2}$ hybridized N donors of the pydridyl groups of adpa, and $2.285 \AA$ to the $\mathrm{sp}^{3}$ hybridized $\mathrm{N}$ donor. The $\mathrm{Zn}-\mathrm{Cl}$ bonds appear normal at 2.285(3) and 2.287(3) ̊. It had been thought that the coordinated chlorides might allow for a $\pi$ contact between the $\mathrm{Zn}$ and the anthracenyl fluorophore, since there would be more space for this than is the case with two chelating nitrates bound to the $\mathrm{Zn}$ [13]. In addition, the structure of the $\mathrm{Zn}$ II addpa complex with coordinated chlorides has the $\mathrm{Zn}$ positioned over the anthracenyl group, albeit with rather long $\mathrm{Zn} \cdots \mathrm{C}$ contacts of $3.40 \AA$ [36]. Thus, it was surmised 
that the $\mathrm{Zn}$ in $\mathbf{3}$ might form a significant $\mathrm{Zn} \cdots \mathrm{C}$ contact. As it turned out, the anthracenyl fluorophore in $\mathbf{3}$ is completely rotated away from the $\mathrm{Zn}^{\mathrm{II}}$, and no $\pi$ contact is present. Structure of $\left[\mathbf{C d}(\mathbf{a d p a}) \mathbf{S}_{2} \mathbf{O}_{3}\right]_{2}(\mathbf{4})$ : The structure of $\mathbf{4}$ is seen in Figure 9. The structure is a dimer with two $\mathrm{S}_{2} \mathrm{O}_{3}{ }^{2-}$ bridges between the two $\mathrm{Cd}^{\mathrm{II}}$ ions forming the dimer. Each $\mathrm{Cd}$ is bonded to one $\mathrm{S}$ from one bridging $\mathrm{S}_{2} \mathrm{O}_{3}{ }^{2-}$ group, and one $\mathrm{O}$ from the other bridging $\mathrm{S}_{2} \mathrm{O}_{3}{ }^{2-}$ group. Including the three $\mathrm{N}$ donors from the adpa, and the rather long $\mathrm{Cd} \cdots \mathrm{C} \pi$ contact of $3.479 \AA$, each $\mathrm{Cd}^{\mathrm{II}}$ in $\mathbf{4}$ can be regarded as six-coordinate. Although strictly a $\pi$ contact is considered to be present only when the M $\cdots \mathrm{C}$ contact distance is less than the sum of the v.d. Waals radii, numerous structures, such as for $\left[\mathrm{Cd}(\mathrm{adpa}) \mathrm{I}_{2}\right]$ above, and structure $\mathbf{4}$ here, where the $\mathrm{C}$ from the long $\pi$ contact occupies a coordination site on the metal, so that one needs to apply a broader criterion for the presence of a $\pi$ contact in many cases [13]. The important point is that short $\mathrm{Cd} \cdots \mathrm{C} \pi$ contacts such as that in $\left[\mathrm{Cd}(\operatorname{adpa})\left(\mathrm{NO}_{3}\right)_{2}\right]$ of $3.018 \AA$ are accompanied by some fluorescence quenching, whereas the long $\pi$ contacts of $3.479 \AA$ in $\mathbf{4}$ are accompanied by a considerable increase in fluorescence intensity [13] .

Absorbance spectra of adpa complexes: The ability of metal ions to quench the fluorescence of PET sensors such as adpa appears to depend on their ability to form $\pi$ contacts in the order $\mathrm{Ni}^{\mathrm{II}} \sim$ $\mathrm{Zn}^{\mathrm{II}}<<\mathrm{Cd}^{\mathrm{II}}<\mathrm{Pb}^{\mathrm{II}}<\mathrm{Hg}^{\mathrm{II}}<\mathrm{Pd}^{\mathrm{II}} \sim \mathrm{Cu}^{\mathrm{II}} \sim \mathrm{Ag}^{\mathrm{I}}$, as well as on a redox mechanism for paramagnetic metal ions such as $\mathrm{Ni}^{\mathrm{II}}$ and $\mathrm{Cu}^{\mathrm{II}}$ that does not require a $\pi$-contact for quenching [11-15]. The evidence for $\pi$-contacts with the fluorophore in the $\mathrm{Cd}^{\mathrm{II}}, \mathrm{Pb}^{\mathrm{II}}, \mathrm{Hg}^{\mathrm{II}}, \mathrm{Pd}^{\mathrm{II}}$ and $\mathrm{Ag}^{\mathrm{I}}$ complexes depends on solid state structures [11-13] and the structures of these adpa complexes in solution may not be the same as the solid state structures. A case in point is the $\mathrm{Cu}^{\mathrm{II}}$ (adpa) complex, which in the solid state does not show a $\pi$ contact in either of the reported structures [11,37], but all other evidence, including a large number of solid state structures of $\mathrm{Cu}^{\mathrm{II}}$ complexes of sensors 

complexes. DFT calculations suggest that the energies of formation of $\pi$ contacts are quite small [14] and so such contacts might easily be overcome by other forces in the crystal lattice.

One can also argue that it is not certain whether fluorescence quenching represents complex-formation with the fluorophore, referred to as 'static quenching' [39] or some other mechanism such as collisional quenching, referred to as 'dynamic quenching' [39]. One might imagine that quenching in solution could be produced by collisions between the fluorophore of adpa and the complexed metal ion, without any actual formation of a long-lived $\pi$ contact. Lakowicz [39] has pointed out that it is not easy to distinguish between static and dynamic quenching. Stern-Volmer plots do not distinguish between weak static quenching and dynamic quenching, since both can be linear [39]. However, one would expect that dynamic, or collisional quenching, would decrease the intensity of the fluorescence without altering the appearance of the absorbance spectrum. Alteration of the absorbance spectrum would require changes in electronic structure in the vicinity of the HOMO and LUMO of the fluorophore, which can be caused by, for example, overlap of the metal orbitals with the $\pi$-orbitals of the fluorophore via a $\pi$ contact. On the other hand, collisional quenching is envisaged as a collision between quencher and fluorophore that does not induce any change in electronic structure of the fluorophore.

In Figure 10 are shown the absorbance spectra of adpa complexed by various metal ions. One sees that the $\pi \rightarrow \pi^{*}$ transitions, which are due to the anthracenyl group, move to longer wavelength with the metal ion adpa complex in the order $\mathrm{Zn}^{\mathrm{II}} \sim \mathrm{Cd}^{\mathrm{II}}<\mathrm{Ag}^{\mathrm{I}}<\mathrm{Pb}^{\mathrm{II}}<\mathrm{Cu}^{\mathrm{II}}<\mathrm{Hg}^{\mathrm{II}}$. This resembles the order of ability of forming $\pi$ contacts in solution noted above, except that $\mathrm{Ag}^{\mathrm{I}}$ occupies a much lower position in the order. This is because the shifts in the $\pi \rightarrow \pi^{*}$ transitions of the absorbance spectra reflect the strength of interaction of the metal ion with the $\pi$ system of the 
fluorophore, whereas the order of ability to form $\pi$ contacts in solution also involves the energy required to displace a coordinated solvent molecule from the metal ion in order to form the $\pi$ contact. The shifts in the $\pi \rightarrow \pi^{*}$ transitions of the absorbance spectra of the adpa complexes thus support the idea that static quenching is occurring, i.e. that $\pi$ contact causing fluorescence quenching is present in solution. It is noteworthy that the large shifts in the $\pi \rightarrow \pi^{*}$ transitions of the $\mathrm{Cu}^{\text {II }}$ (adpa) complex support the idea that a $\pi$ contact is present in solution, even though the solid state structures do not. It should be noted that changes in fluorescence spectra due to complex formation of adpa with metal ions are accompanied by shifts in peak positions, and often a complete change in the appearance of the fluorescence spectrum. This is also consistent with static quenching, caused by the formation of $\pi$ contacts between the metal ion and the fluorophore.

In Figure 11, we show the absorbance spectra of the $2 \times 10^{-5} \mathrm{M} \mathrm{Cd}^{\mathrm{II}}$ (adpa) complex as a function of $\mathrm{NaI}$ concentration. The change in the absorbance spectra as iodide concentration increases resembles quite strongly the changes that occur in Figure 10. The spectra in Figure 11 can be analyzed (Figure S1) to yield $\log \mathrm{K}_{1}=4.50$ and $\log \mathrm{K}_{2}=2.75$ for binding of $\mathrm{I}^{-}$to the $\mathrm{Cd}^{\mathrm{II}}$ (adpa) complex, as was done for the corresponding set of fluorescence spectra in Figure 3, which gave $\log \mathrm{K}_{1}=4.56$ and $\log \mathrm{K}_{2}=2.51$. This level of agreement between $\log \mathrm{K}$ values derived from fluorescence and from other techniques such as absorbance spectroscopy is quite satisfactory, considering there can be large differences between such measurements: fluorescence spectroscopy yields log $\mathrm{K}$ values that refer to the excited state, whereas absorbance and other techniques refer to the ground state [39]. The changes in the absorbance spectra in Figure 11 as the $\mathrm{Cd}^{\mathrm{II}}$ (adpa) complex is titrated with iodide would seem to support the idea that the strong quenching of fluorescence observed in a similar titration in Figure 3 is caused by a 

contact between $\mathrm{I}^{-}$and the anthracenyl fluorophore is expected to be weak, if anything, according to the crystal structure. Therefore, it remains to be seen (via DFT calculations) whether such a weak $\pi$ contact is responsible for strong static quenching by $\mathrm{I}^{-}$of the $\mathrm{Cd}^{\mathrm{II}}$ (adpa) complex.

Since all the evidence to date suggests that the $\mathrm{Zn}^{\mathrm{II}}$ (adpa) complex does not have any $\pi$ contacts to disrupt, and the anthracenyl fluorophore is rotated away from the $\mathrm{Zn}{ }^{\mathrm{II}}$ binding site (Figure. 8), one might expect that the fluorophore is not perturbed by iodide binding, and titration with iodide would not have the same effect on the absorbance spectrum of the complex. This is what is found for the absorbance spectrum of the $\mathrm{Zn}^{\mathrm{II}}$ (adpa) complex, which shows almost no response to titration with I (Figure S2). This should be the best test for distinguishing collisional quenching from other mechanisms involving complex formation - a lack of response of the absorbance spectrum of the fluorophore to titration with a fluorescence-quenching species, in this case, $\mathrm{I}^{-}$. The quenching of fluorescence of $\mathrm{Zn}^{\mathrm{II}}$ (adpa) by $\mathrm{I}^{-}$in Figure 5 yields a SternVolmer plot that is reasonably linear (Figure S3), which by itself is not diagnostic of collisional quenching [42]. However, the fact that quenching occurs without change in appearance of the fluorescence spectrum, and the absorbance spectra do not respond significantly to titration with $\mathrm{I}^{-}$ strongly supports the idea that the quenching of the fluorescence of $\mathrm{Zn}^{\mathrm{II}}$ (adpa) by $\mathrm{I}^{-}$is due to collisional quenching. In contrast, the quenching of the fluorescence of $\mathrm{Cd}^{\mathrm{II}}$ (adpa) by $\mathrm{I}^{-}$is accompanied by a change in the appearance of the fluorescence spectrum. The absorbance spectra also show large changes in peak position and appearance on titration with iodide, and the Stern-Volmer plot is far from linear, being strongly curved downwards with a double humped appearance (Figure S4). This suggests that the quenching mechanisms associated with the binding of iodide anion to $\mathrm{Cd}^{\mathrm{II}}$ (adpa) complex and $\mathrm{Zn}^{\mathrm{II}}$ (adpa) are not the same. 


\section{Density functional theory (DFT) studies:}

Based on our fluorescence and absorbance studies, we believe that the strong quenching of fluorescence of the $\mathrm{Cd}^{\mathrm{II}}$ (adpa) complex due to I' occurs via static quenching. One possible source of quenching is the $\pi$ contacts between the coordinated $\mathrm{I}^{-}$and the fluorophore. However, the I $\cdots \mathrm{C}$ distance is slightly larger than the sum of the van der Waals radii of the two atoms and the $\pi$ contact between the fluorophore and $\mathrm{I}^{-}$might be too weak to cause strong quenching seen in Figure 3. In order to identify the quenching mechanism associated with $\mathrm{I}^{-}$ion, we carried out DFT and time-dependent DFT studies of three complexes: $\mathrm{Cd}^{\mathrm{II}}(\operatorname{adpa}), \mathrm{Cd}^{\mathrm{II}}(\operatorname{adpa}) \mathrm{Cl}_{2}$, and $\mathrm{Cd}^{\mathrm{II}}(\mathrm{adpa}) \mathrm{I}_{2}$. Because the X-ray study of the $\mathrm{Cd}_{\mathrm{II}}(\operatorname{adpa}) \mathrm{Cl}_{2}$ complex showed two different structures, one with $\pi$ contacts and another without a $\pi$ contact between $\mathrm{Cd}^{\mathrm{II}}$ and the fluorophore, we considered both possibilities. Since $\mathrm{Cd}^{\mathrm{II}}$ is typically 6-coordinate, water molecules were added to complete the coordination shell. For the structures with $\mathrm{M} \cdots \mathrm{C} \pi$ contacts, the fluorophore is considered to be one of the coordinating ligands, and therefore it has one less water molecule than the corresponding structure without a $\pi$ contact. The list of complexes studied via DFT/TDDFT is found in Table 2.

We first optimized the ground state geometry of each complex, starting from a variety of possible $\mathrm{Cd}^{\mathrm{II}}$ (adpa)-ligand conformations. In Figure 12 are shown the optimized structures of the $\mathrm{Cd}^{\mathrm{II}}(\mathrm{adpa}) \mathrm{Cl}_{2}$ complex with and without a $\pi$ contact. For the structure without a $\pi$ contact, the anthracenyl group turns away from the metal and the $6^{\text {th }}$ coordination site is occupied by a water molecule (i.e. $\left.\mathrm{Cd}^{\mathrm{II}}(\operatorname{adpa}) \mathrm{Cl}_{2}\left(\mathrm{H}_{2} \mathrm{O}\right)\right)$. The optimized ground state structure of $\mathrm{Cd}^{\mathrm{II}}(\operatorname{adpa}) \mathrm{Cl}_{2}\left(\mathrm{H}_{2} \mathrm{O}\right)$ without a $\pi$ contact has two pyridyl groups at almost right angles (Figure 12 (a)), which is consistent with the X-ray structure. Similar optimized structures were found for the 

distortion of the chelate rings involving the two pyridyl groups increases as halide ions replace water. This can be seen by the N-Cd-N angle, which decreases from $112^{\circ}\left(\mathrm{Cd}^{\mathrm{II}}(\operatorname{adpa})\left(\mathrm{H}_{2} \mathrm{O}\right)_{3}\right)$. to $98^{\circ}\left(\mathrm{Cd}^{\mathrm{II}}(\operatorname{adpa}) \mathrm{Cl}_{2}\left(\mathrm{H}_{2} \mathrm{O}\right)\right)$, and then to $95^{\circ}\left(\mathrm{Cd}^{\mathrm{II}}(\operatorname{adpa}) \mathrm{I}_{2}\left(\mathrm{H}_{2} \mathrm{O}\right)\right)$ as a water molecule is replaced by $\mathrm{Cl}^{-}$and $\mathrm{I}^{-}$. The $\mathrm{Cd}^{\mathrm{II}}(\operatorname{adpa}) \mathrm{Cl}_{2}\left(\mathrm{H}_{2} \mathrm{O}\right)$ structure that resembles the X-ray structure of $\mathrm{Zn}^{\mathrm{II}}(\operatorname{adpa}) \mathrm{Cl}_{2}$ (Figure. 12(b)) with no $\pi$ contact, where two pyridyl groups are roughly in the same plane, is less stable by $4.9 \mathrm{kcal} / \mathrm{mol}$ than the ground state structure. The corresponding energy difference for the $\mathrm{Cd}^{\mathrm{II}}(\operatorname{adpa}) \mathrm{I}_{2}\left(\mathrm{H}_{2} \mathrm{O}\right)$ complex and $\mathrm{Cd}^{\mathrm{II}}(\operatorname{adpa})\left(\mathrm{H}_{2} \mathrm{O}\right)_{3}$ complex is 7.9 and $1.8 \mathrm{kcal} / \mathrm{mol}$, respectively. Thus, it seems that the coordination of a larger and softer ligand favors the distorted structure with two pyridyl groups roughly at right angles.

Since the numbers of water molecules are not the same between the $\pi$-contacted (Figure 12(c)) and non- $\pi$-contacted structures (Figure 12(a)), direct comparison of their stabilities in solution is not trivial. A simple comparison of the energy of non- $\pi$-contacted $\mathrm{Cd}^{\mathrm{II}}(\operatorname{adpa})\left(\mathrm{H}_{2} \mathrm{O}\right)_{3}$ and the sum of the energies of $\pi$-contacted $\mathrm{Cd}^{\mathrm{II}}(\operatorname{adpa})\left(\mathrm{H}_{2} \mathrm{O}\right)_{2}$ and a water molecule (i.e. $E\left[\mathrm{Cd}^{\mathrm{II}}(\operatorname{adpa})\left(\mathrm{H}_{2} \mathrm{O}\right)_{3}\right]$ vs. $\left.E\left[\mathrm{Cd}^{\mathrm{II}}(\operatorname{adpa})\left(\mathrm{H}_{2} \mathrm{O}\right)_{2}\right]+E\left[\mathrm{H}_{2} \mathrm{O}\right]\right)$ indicates that the non- $\pi$-contacted structure is more stable by $7.5 \mathrm{kcal} / \mathrm{mol}$, which is not surprising given that $\mathrm{Cd}^{\mathrm{II}}$ is at the weaker end of the series for the $\pi$-contact ability. However, care must be taken since the absolute energy difference between two structures obtained from DFT calculations does not include the energy required for a water molecule to break free from the hydrogen bond network of liquid water before it replaces the $\mathrm{M} \cdots \mathrm{C} \pi$ contact. Thus, the energy difference between the two structures in solution could be smaller. In fact, as the X-ray structure of the $\mathrm{Cd}$ (II adpa) $\mathrm{Cl}_{2}$ complex indicates, it is likely that the two structures coexist in solution. Although the absolute energy difference obtained from DFT calculations between the $\pi$-contacted and non- $\pi$-contacted structures does 
not directly tell us their relative stabilities in solution, it is interesting and important to note that such energy differences increase when halide ions are coordinated to $\mathrm{Cd}^{\mathrm{II}}$ instead of water. More specifically, the energy difference between the two structures, $\pi$-contacted and non- $\pi$-contacted, becomes $11.3 \mathrm{kcal} / \mathrm{mol}$ for the $\mathrm{Cd}^{\mathrm{II}}(\mathrm{adpa}) \mathrm{Cl}_{2}$ complex and $11.0 \mathrm{kcal} / \mathrm{mol}$ for the $\mathrm{Cd}^{\mathrm{II}}(\operatorname{adpa}) \mathrm{I}_{2}$ complex. This clearly indicates that the relative stability of the non- $\pi$-contacted structure increases and the equilibrium between two structures will be further shifted toward the non- $\pi$ contacted one as halide ions bind to $\mathrm{Cd}^{\mathrm{II}}$.

In addition to the ground state, we also optimized the structure of the excited state $\left(\mathrm{S}_{1}\right)$ using the TDDFT approach for each complex, which is needed to compute the fluorescence intensities. We considered a variety of different ligand arrangements as starting geometries for each complex. In general, there is little structural change upon excitation and the non- $\pi$ contacted conformation is more stable than the $\pi$-contacted one for all complexes in the excited state as well. Although structural change is generally minimal, the changes seen in the non- $\pi$-contacted form of $\mathrm{Cd}^{\mathrm{II}}(\mathrm{adpa}) \mathrm{I}_{2}\left(\mathrm{H}_{2} \mathrm{O}\right)$ are more noticeable than others (See Figure S6 for the excited state geometries). In particular, the distance between the two iodide ions decreases from $4.70 \AA$ to $3.36 \AA$ upon excitation to the $\mathrm{S}_{1}$ state and the coordinating water molecule moves away from the fluorophore. The N-Cd-N angle also increases from $95^{\circ}$ to $108^{\circ}$. For all other complexes listed in Table 1, the changes in bond length and angles upon excitation are less than $0.1 \AA$ and $1^{\circ}$, respectively.

With the optimized ground and excited state geometries, we computed the oscillator strengths associated with the absorption $\left(S_{0} \rightarrow S_{1}\right)$ and emission $\left(S_{1} \rightarrow S_{0}\right)$ for both the $\pi$ contacted and non- $\pi$-contacted structures of each complex. Specifically, a TDDFT calculation was performed with the ground state geometry for the absorption intensity and with the excited 
state geometry for the emission intensity. The results of these calculations are summarized in Table 2. For the $\mathrm{Cd}^{\mathrm{II}}$ (adpa) complex without halide ions, both the $\pi$-contacted and non- $\pi$ contacted structures are fluorescent, but the $\pi$-contacted one has a considerably smaller oscillator strength. This might explain the observed $30 \%$ decreases in the fluorescent intensity of the $\mathrm{Cd}^{\mathrm{II}}(\mathrm{adpa})$ complex with respect to that of the $\mathrm{Zn}^{\mathrm{II}}$ (adpa) complex. In the case of $\mathrm{Zn}^{\mathrm{II}}$ (adpa) complex, only the non- $\pi$-contacted structure was observed in the X-ray study, whereas a mixture of $\pi$-contacted and non- $\pi$-contacted structures are thought to be present for the $\mathrm{Cd}^{\mathrm{II}}$ (adpa) complex [12].

When chloride ions bind to the $\mathrm{Cd}^{\mathrm{II}}$ (adpa) complex, there is no dramatic change in the computed oscillator strengths for absorption and emission. Although the oscillator strength increases slightly for both $\pi$-contacted and non- $\pi$-contacted structures, such a small increase in oscillator strength alone may not be sufficient to explain the observed increase in fluorescence intensity upon $\mathrm{Cl}^{-}$binding. However, there is a change in the relative stability between the $\pi$ contacted and non- $\pi$-contacted structures. As mentioned above, the relative stability of the non$\pi$-contacted structure with respect to the $\pi$-contacted one increases upon $\mathrm{Cl}^{-}$binding. Thus, the binding of $\mathrm{Cl}^{-}$anion destabilizes the $\pi$-contacted structure and drives the system toward the non$\pi$-contacted one in solution, which shows higher oscillator strengths for both absorption and emission. This is consistent with our proposed sensing mechanism (Scheme 1) and explain the observed increase in fluorescence intensity of $\mathrm{Cd}^{\mathrm{II}}$ (adpa) complex upon $\mathrm{Cl}^{-}$binding.

For the binding of iodide ions, the relative stability of the non- $\pi$-contacted form increases as for the binding of chloride ion. However, there is a subtle difference in the electronic structures between the non- $\pi$-contacted $\mathrm{Cd}^{\mathrm{II}}(\operatorname{adpa}) \mathrm{Cl}_{2}\left(\mathrm{H}_{2} \mathrm{O}\right)$ and $\mathrm{Cd}^{\mathrm{II}}(\operatorname{adpa}) \mathrm{I}_{2}\left(\mathrm{H}_{2} \mathrm{O}\right)$ complexes. As shown in Figure 13(a), the transitions between HOMO and LUMO are contained exclusively 
within the anthracenyl group of $\mathrm{Cd}^{\mathrm{II}}(\mathrm{adpa}) \mathrm{Cl}_{2}\left(\mathrm{H}_{2} \mathrm{O}\right)$ for both absorption and emission. Therefore, the non- $\pi$-contacted $\mathrm{Cd}^{\mathrm{II}}(\operatorname{adpa}) \mathrm{Cl}_{2}\left(\mathrm{H}_{2} \mathrm{O}\right)$ is fluorescent with a large oscillator strength. In contrast, the characteristics of molecular orbitals in the vicinity of fluorophore HOMO and LUMO change upon excitation for the $\mathrm{Cd}^{\mathrm{II}}(\operatorname{adpa}) \mathrm{I}_{2}\left(\mathrm{H}_{2} \mathrm{O}\right)$ complex. In the ground state, the HOMO and LUMO of the complex are localized on the anthracenyl fluorophore and, thus, absorption $\left(\mathrm{S}_{0} \rightarrow \mathrm{S}_{1}\right)$ occurs with a large oscillator strength. However, as mentioned above, there is structural change in the excited state, which is accompanied by reordering of frontier molecular orbitals. The HOMO of the complex is now localized at the iodide, but the LUMO is located on the fluorophore (Figure 13(b)). Therefore, the $S_{1} \rightarrow S_{0}$ transition involves a charge transfer from the anthracenyl fluorophore to the iodide, which is forbidden as indicated by the negligibly small oscillator strength. As a result, driving the system from the $\pi$-contacted to the non- $\pi$-contacted structure via iodide binding leads to fluorescence quenching. For $\pi$-contacted structures, there is very little structural change upon excitation for both $\mathrm{Cd}^{\mathrm{II}}(\operatorname{adpa}) \mathrm{Cl}_{2}\left(\mathrm{H}_{2} \mathrm{O}\right)$ and $\mathrm{Cd}^{\mathrm{II}}(\mathrm{adpa}) \mathrm{I}_{2}\left(\mathrm{H}_{2} \mathrm{O}\right)$ and the HOMO and LUMO remain on the fluorophore (Figure S7). Therefore, they are fluorescent, although their oscillator strengths are smaller than those of non- $\pi$-contacted ones.

In summary, the fluorescence quenching due to iodide binding to the $\mathrm{Cd}^{\mathrm{II}}$ (adpa) complex is probably not because of the weak $\pi$ contact between the iodide ions and fluorophore according to our DFT calculations. It seems that there are two factors that are responsible for the observed fluorescence quenching in the $\mathrm{Cd}^{\mathrm{II}}(\operatorname{adpa}) \mathrm{I}_{2}$ complex. First, the relative stability of the non- $\pi$ contacted structure over the $\pi$-contacted one increases as iodide ions bind to the complex, which is expected considering the steric crowding caused by the iodide ions. Second, the non- $\pi$ contacted $\mathrm{Cd}^{\mathrm{II}}(\mathrm{adpa}) \mathrm{I}_{2}$ complex is not fluorescent, with a negligibly small oscillator strength. 

the fluorescence intensity should decrease.

\section{CONCLUSIONS}

Both collisional quenching and static quenching involving weak complex-formation in solution can produce linear Stern-Volmer plots [39]. One can distinguish between collisional quenching and static quenching in that the former affects only the excited state, and so does not affect absorbance spectra due to the fluorophore. Static quenching affects both the ground and excited states, and so affects both the absorbance and fluorescence spectra due to the fluorophore.

The absorbance spectra of adpa complexes in solution shift to longer wavelength upon binding to metal ions, and the extent of shifting matches the proposed order of strength with which the metal ions form $\pi$ contacts, supporting the idea that the quenching of the fluorescence is static, and involves the formation of $\pi$ contacts in the ground state in adpa/metal ion complexes in solution. When $\mathrm{I}^{-}$is added to the solution, the fluorescence of the $\mathrm{Zn}{ }^{\mathrm{II}}$ adpa complex is weakly quenched, but this is not accompanied by a change in the absorbance spectrum of the $\mathrm{Zn}^{\mathrm{II}}$ (adpa) complex, and the quenching yields a linear Stern-Volmer plot. Thus, one concludes that this is an example of collisional quenching. On the other hand, the strong quenching of the fluorescence of the $\mathrm{Cd}^{\mathrm{II}}$ (adpa) complex by coordination of iodide may occur through a different mechanism. The crystal structure of $\left[\mathrm{Cd}(\mathrm{adpa}) \mathrm{I}_{2}\right](\mathbf{1})$ suggests that there might be a weak $\pi$ contact between a coordinated iodide and the anthracenyl fluorophore of the adpa, which can cause fluorescence quenching. However, the $\mathrm{I} \cdots \mathrm{C}$ distance seems to be too long to cause strong quenching. The DFT calculations showed that the population of the non- $\pi$ contacted structure should increase upon iodide binding as expected, but, unlike $\mathrm{Cd}{ }^{\mathrm{II}}(\mathrm{adpa}) \mathrm{Cl}_{2}$, 


\begin{abstract}
the non- $\pi$-contacted form of $\mathrm{Cd}^{\mathrm{II}}(\mathrm{adpa}) \mathrm{I}_{2}$ is not fluorescent. This is due to the structural change in the excited state where the $S_{1} \rightarrow S_{0}$ transition becomes a charge transfer transition from the fluorophore to the iodide, which transition has a negligibly small oscillator strength.
\end{abstract}

\begin{abstract}
Appendix A. Supplementary Data: The CCDC contains the supplementray crystallographic data as numbers 1523353-1523355. These data can be downloaded free of charge via http://www.ccdc.cam.ac.uk/conts/retrieving.html, or from the Cambridge Crystallographic Data Centre, 12 Union Road, Cambridge CB2 1EZ, UK; fax (+44) 1223-336-033; or email: deposit@ccdc.cam.ac.uk.
\end{abstract}

\title{
ACKNOWLEDGEMENTS:
}

This paper is based upon work supported by the National Science Foundation under CHE 1565981. The authors also thank the University of North Carolina Wilmington for support for this work, and a bursary to JWN. 


\section{REFERENCES}

1) N. Zacchiarias, D. A. Dougherty, Trends Pharmacol. Sci. 23, 281 (2002).

2) G. W. Gokel, Chem. Commun., 23, 2847 (2003).

3) D. Umadevi, S. Panigrahi, N. Sastry, Acc. Chem. Res., 47, 2574 (2014).

4) S. A. Wheeler, Acc. Chem. Res., 46, 1029 (2013).

5) J. L. Asensio, A. Arda., F. J. Canada, J. Jimenez-Barberi, Acc. Chem. Res., 46, 946 (2013).

6) H. T. Chifotides, K. R. Dunbar, Acc. Chem. Res., 46, 894 (2013).

7) P. Politzer, J. S. Murray, T. Clark, Phys. Chem. Chem. Phys., 12, 7748 (2010).

8) A. K. Tewari, P. Srivastava, V. P. Singh, P. Singh, R. S. Khanna, Res. Chem. Intermed., 39, 2925 (2005).

9) R. Dubey, D. Lim. Curr. Org. Chem., 15, 2072 (2011).

10) C. Janiak, Dalton, 21, 3885 (2000).

11) H. Lee, H.-S. Lee, J. H. Reibenspies, R. D. Hancock, Inorg. Chem., 51, 10904 (2012).

12) J. W. Nugent, H. Lee, H.-S. Lee, J. H. Reibenspies, R. D. Hancock, Chem. Comm., 49, 9749 (2013).

13) J. W. Nugent, H. Lee, H.-S. Lee, J. H. Reibenspies, R. D. Hancock, Inorg. Chem., 53, 9014 (2014).

14) H. Lee, R.D. Hancock, H.-S. Lee, J. Phys. Chem. A., 117, 13345 (2013).

15) R. D. Hancock, Chem. Soc. Rev., 42, 1500 (2013).

16) M. E. Huston, C. Engleman, A. W. Czarnik, J. Am. Chem. Soc., 112, 7054 (1990).

17) A. W. Czarnik, Trends Org. Chem., 4, 123 (1993).

18) Cambridge Structural Database, Cambridge Crystallographic Data Centre, 12 Union Road, Cambridge CB2 1EZ, United Kingdom. 2013.

19) R. D. Hancock, J. H. Reibenspies, H. Maumela, Inorg. Chem., 43, 298 (2004).

20) R. Luckay, I. Cukrowski, J. Mashishi, J. H. Reibenspies, A. H. Bond, R. D. Rogers, R. D. Hancock, J. Chem. Soc., Dalton Trans., 90, 1997.

21) N. N. Greenwood, A. Earnshaw, Chemistry of the Elements, $2^{\text {nd }}$ Edition, Butterworth, Oxford UK, 2001, p. 1218.

22) A. Ojida, Y. Mito-Oka, M. Inoue, I. Hamachi, J. Am. Chem. Soc., 124, 6256 (2002).

23) J. I. Hedges, J. H. Stern, Limnol. Oceanogr., 29, 663 (1984).

24) E. J. Gabe, Y. Le Page, J.-P. Charland, F. L. Lee, P. S. White, J. Appl. Cryst., 22, 384 (1989). 
25) M. W. Schmidt, K. K. Baldridge, J. A. Boatz, S. T. Elbert, M. S. Gordon, J. H. Jensen, S. Koseki, N. Matsunaga, K. A. Nguyen, S. Su, T. L. Windus, M. Dupuis, J. A. Montgomery, J. Comp. Chem., 14, 1347 (1993).

26) C. Lee, W. Yang, R. G. Parr, Phys. Rev. B, 37, 785 (1988).

27) A. D. Becke, J. Chem. Phys., 98, 5648 (1993).

28) F. Weigend, R. Ahlrichs, Phys. Chem. Chem. Phys., 7, 3297 (2005).

29) P. J. Hay, W. R. Wadt, J. Chem. Phys., 82, 270 (1985).

30) P. J. Hay, W. R. Wadt, J. Chem. Phys., 82, 284 (1985).

31) P. J. Hay, W. R. Wadt, J. Chem. Phys., 82, 299 (1985).

32) E. J. Billo, EXCEL for Chemists, Wiley VCH: New York, 2001.

33) ORTEP-3 for Windows, version 1.08, L. J. Farrugia, J. Appl. Crystallogr., 30, 565 (1997).

34) A. Bondi, J. Phys. Chem., 68, 441 (1964).

35) M. Mirzaei, H. Eshtiagh-Hosseini, M. M. Abadeh, M. Chahkandi, A. Frontera, A. Hassanpoor, Cryst. Eng. Comm., 15, 1404 (2013).

36) K. Kubo, A. Mori, J. Mater. Chem., 15, 2902 (2005).

37) B. Antonioli, B. Buchner, J. K. Clegg, K. Gloe, K. Gloe, L. Gotzke, A. Heine, A. Jager, K. A. Jolliffe, O. Kataeva, V. Kataev, R. Klingeler, T. Krause, L. F. Lindoy, A. Popa, W. Seichter, M. Wenzel, Dalton Trans., 4795 (2009).

38) M. J. Kim, K. M. K. Swamy, K. M. Lee, A. R. Jagdale, Y. Kim, S.-J. Kim, K. H. Yoo, J. Yoon, Chem. Comm., 7215 (2009).

39) J. R. Lakowicz, Principles of Fluorescence Spectroscopy, 3rd Edition, Springer, New York, 2006. 
Table 1. Crystal data and details of structure refinement for $\left[\mathrm{Cd}(\mathrm{cdpa}) \mathrm{I}_{2}\right](\mathbf{1}),\left[\mathrm{Hg}(\mathrm{adpa}) \mathrm{I}_{2}\right](\mathbf{2})$, $\left[\mathrm{Zn}(\mathrm{adpa}) \mathrm{Cl}_{2}\right]\left(\mathrm{H}_{2} \mathrm{O}\right)_{2}(\mathbf{3})$, and $\left[\mathrm{Cd}(\operatorname{adpa}) \mathrm{S}_{2} \mathrm{O}_{3}\right]_{2}(\mathbf{4})$.

\begin{tabular}{|c|c|c|c|c|}
\hline & 1 & 2 & 3 & 4 \\
\hline Empirical formula: & $\mathrm{C}_{27} \mathrm{H}_{23} \mathrm{CdI}_{2} \mathrm{~N}_{3}$ & $\mathrm{C}_{27} \mathrm{H}_{23} \mathrm{HgI}_{2} \mathrm{~N}_{3}$ & $\mathrm{C}_{27} \mathrm{H}_{27} \mathrm{ZnCl}_{2} \mathrm{~N}_{3} \mathrm{O}_{2}$ & $\mathrm{C}_{27} \mathrm{H}_{23} \mathrm{CdN}_{3} \mathrm{O}_{3} \mathrm{~S}_{3}$ \\
\hline Formula weight: & 748.66 & 842.86 & 561.78 & 614.00 \\
\hline Temperature (K) & $110(2)$ & $110(2)$ & $110(2)$ & $110(2)$ \\
\hline Wavelength $(\AA)$ : & 0.71073 & 0.71073 & 0.71073 & 0.71073 \\
\hline Crystal system: & monoclinic & monoclinic & orthorhombic & monoclinic \\
\hline Space group: & $P 2_{1} / \mathrm{n}$ & $P 2_{1} / \mathrm{n}$ & Pna21 & $P 2_{l} / c$ \\
\hline \multicolumn{5}{|l|}{ Unit cell dimensions: } \\
\hline$a(\AA)$ & $10.6342(3)$ & $9.7331(3)$ & $19.9642(7)$ & $9.391(2)$ \\
\hline$b(\AA)$ & $21.847(3)$ & $13.0935(4)$ & $14.6657(3)$ & $31.883(6)$ \\
\hline$c(\AA)$ & 11.1071(16) & $21.20340(7)$ & $8.7946(5)$ & $8.9641(16)$ \\
\hline$\alpha(\mathrm{deg})$ & 90 & 90 & 90 & 90 \\
\hline$\beta(\operatorname{deg})$ & $100.446(7)$ & $99.9990(15)$ & 90 & $97.848(16)$ \\
\hline$\gamma(\operatorname{deg})$ & 90 & 90 & 90 & 90 \\
\hline Volume $\left(\AA^{3}\right)$ : & $2537.7(6)$ & 2638.61(14) & $2574.96(18)$ & $2658.8(10)$ \\
\hline Z & 4 & 4 & 4 & 4 \\
\hline Final $\mathrm{R}$ indices & $R 1=0.0245$ & $R 1=0.0265$ & $R 1=0.0334$ & $R 1=0.0727$ \\
\hline$[I>2 \sigma(I)]$ & $w R 2=0.0461$ & $w R 2==0.0662$ & $w R 2=0.0840$ & $w R 2=0.1642$ \\
\hline $\mathrm{R}$ indices (all data) & $\begin{array}{l}R 1=0.0309 \\
w R 2=0.0479\end{array}$ & $\begin{array}{l}R 1=0.0330 \\
w R 2=0.0687\end{array}$ & $\begin{array}{l}R 1=0.0381 \\
w R 2=0.0856\end{array}$ & $\begin{array}{c}R 1=0.1243 \\
w R 2=0.1750\end{array}$ \\
\hline
\end{tabular}


Table 2. Oscillator strengths for the $\mathrm{S}_{0} \rightarrow \mathrm{S}_{1}$ (absorption) and $\mathrm{S}_{1} \rightarrow \mathrm{S}_{0}$ (emission) transitions computed using the time-dependent DFT method. The $\pi$-contacted structure for a given complex has one less water molecule. For all the transitions reported in the table, the contribution form HOMO $\rightarrow$ LUMO excitation is $98 \%$ or larger.

\begin{tabular}{cccc}
\hline System & $\Delta \mathrm{E}[\mathrm{kcal} / \mathrm{mol}]^{\mathrm{a}}$ & $f\left(\mathrm{~S}_{0} \rightarrow \mathrm{S}_{1}\right)$ & $f\left(\mathrm{~S}_{1} \rightarrow \mathrm{S}_{0}\right)$ \\
\hline $\mathrm{Cd}^{\mathrm{II}}($ adpa $)\left(\mathrm{H}_{2} \mathrm{O}\right)_{2}$ & - & 0.1076 & 0.1064 \\
$\mathrm{Cd}^{\mathrm{II}}($ adpa $)\left(\mathrm{H}_{2} \mathrm{O}\right)_{3}$ & -7.53 & 0.1350 & 0.1305 \\
$\mathrm{Cd}^{\mathrm{II}}($ adpa $) \mathrm{Cl}_{2}$ & - & 0.1116 & 0.1122 \\
$\mathrm{Cd}^{\mathrm{II}}($ adpa $) \mathrm{Cl}_{2}\left(\mathrm{H}_{2} \mathrm{O}\right)$ & -11.31 & 0.1376 & 0.1334 \\
$\mathrm{Cd}($ adpa $) \mathrm{I}_{2}$ & - & 0.1109 & 0.1080 \\
$\mathrm{Cd}^{\mathrm{II}}(\operatorname{adpa}) \mathrm{I}_{2}\left(\mathrm{H}_{2} \mathrm{O}\right)$ & -11.01 & 0.1417 & 0.0001 \\
\hline
\end{tabular}

${ }^{a}$ Energy difference between the $\pi$-contacted and non- $\pi$-contacted structure: $E\left[C d^{\mathrm{II}}(\operatorname{adpa}) \mathrm{X}_{2}\left(\mathrm{H}_{2} \mathrm{O}\right)\right]-E\left[\mathrm{Cd}^{\mathrm{II}}(\operatorname{adpa}) \mathrm{X}_{2}\right]-E\left[\mathrm{H}_{2} \mathrm{O}\right]$ where $\mathrm{X}=\mathrm{H}_{2} \mathrm{O}, \mathrm{Cl}, \mathrm{I}$. 
<smiles>O=C(O)OCc1ccccn1</smiles><smiles>O=C(O)OC(=O)C(=O)O</smiles><smiles>OCCOC(O)(O)O</smiles>

Figure 1. Structures of ligands discussed in this paper. 


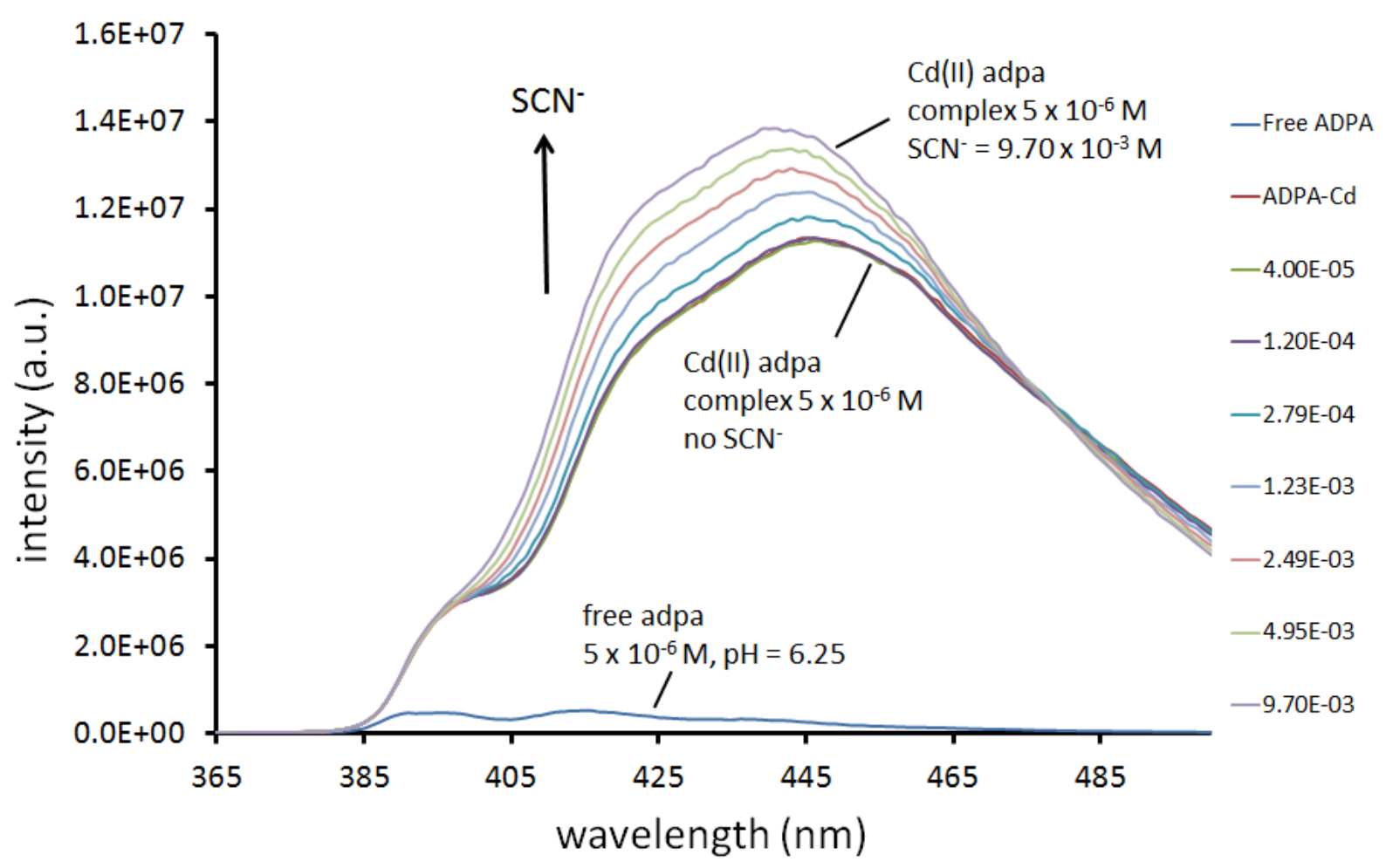

Figure 2. Effect of $\mathrm{SCN}^{-}$concentration on the fluorescence intensity of $5 \times 10^{-6} \mathrm{M} \mathrm{Cd}^{\mathrm{II}}$ (adpa) complex in $50 \% \mathrm{MeOH} / \mathrm{H}_{2} \mathrm{O}$ at $\mathrm{pH} 6.25$ and $25^{\circ} \mathrm{C}$. Excitation wavelength $=350 \mathrm{~nm}$. 


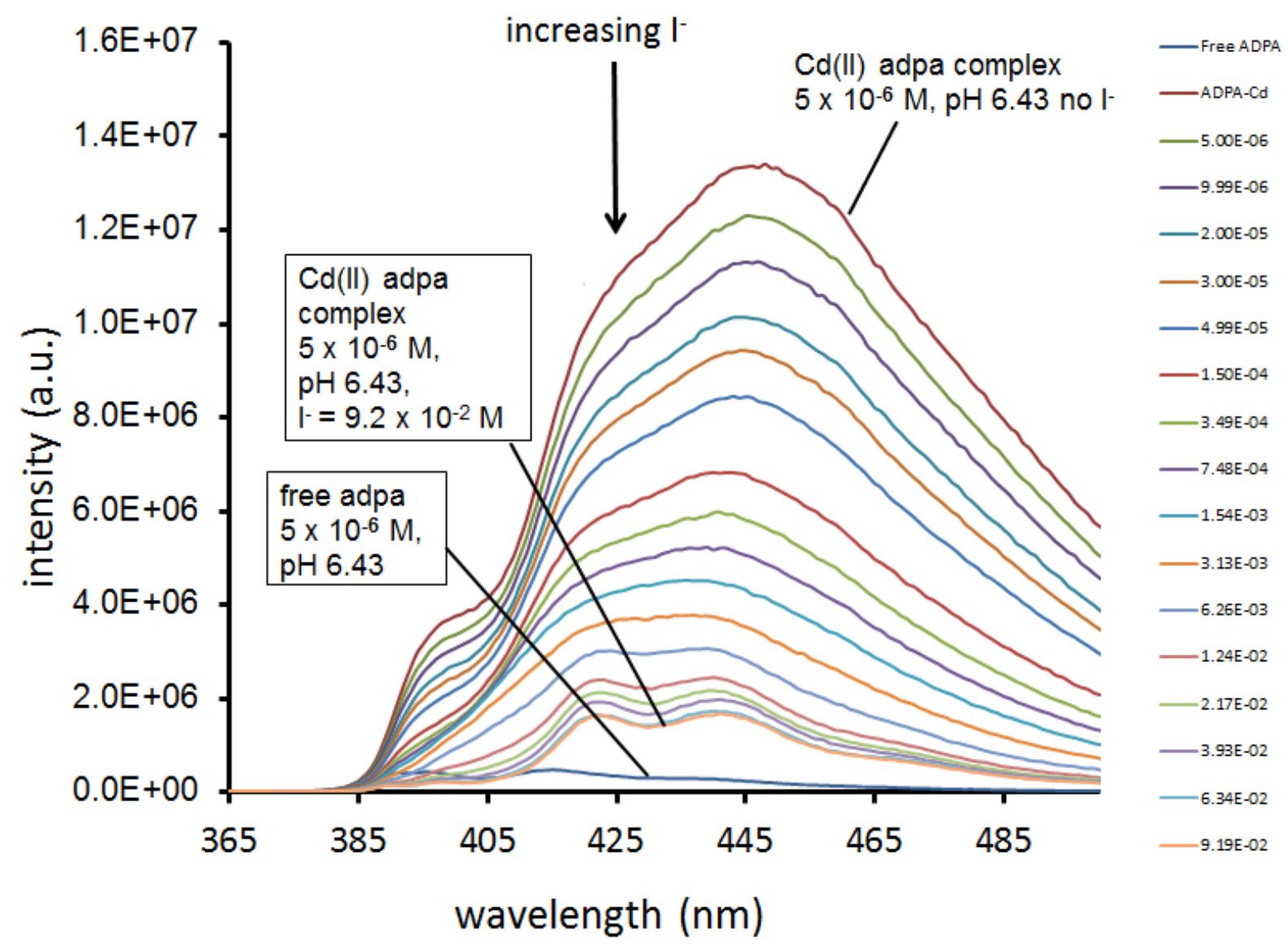

Figure 3. Effect of added $\mathrm{I}^{-}$on the fluorescence intensity of $5 \times 10^{-6} \mathrm{M} \mathrm{Cd}^{\mathrm{II}}$ (adpa) complex in $50 \% \mathrm{MeOH} / \mathrm{H}_{2} \mathrm{O}$ at $\mathrm{pH} 6.43$ and $25{ }^{\circ} \mathrm{C}$. Excitation wavelength $=350 \mathrm{~nm}$. 


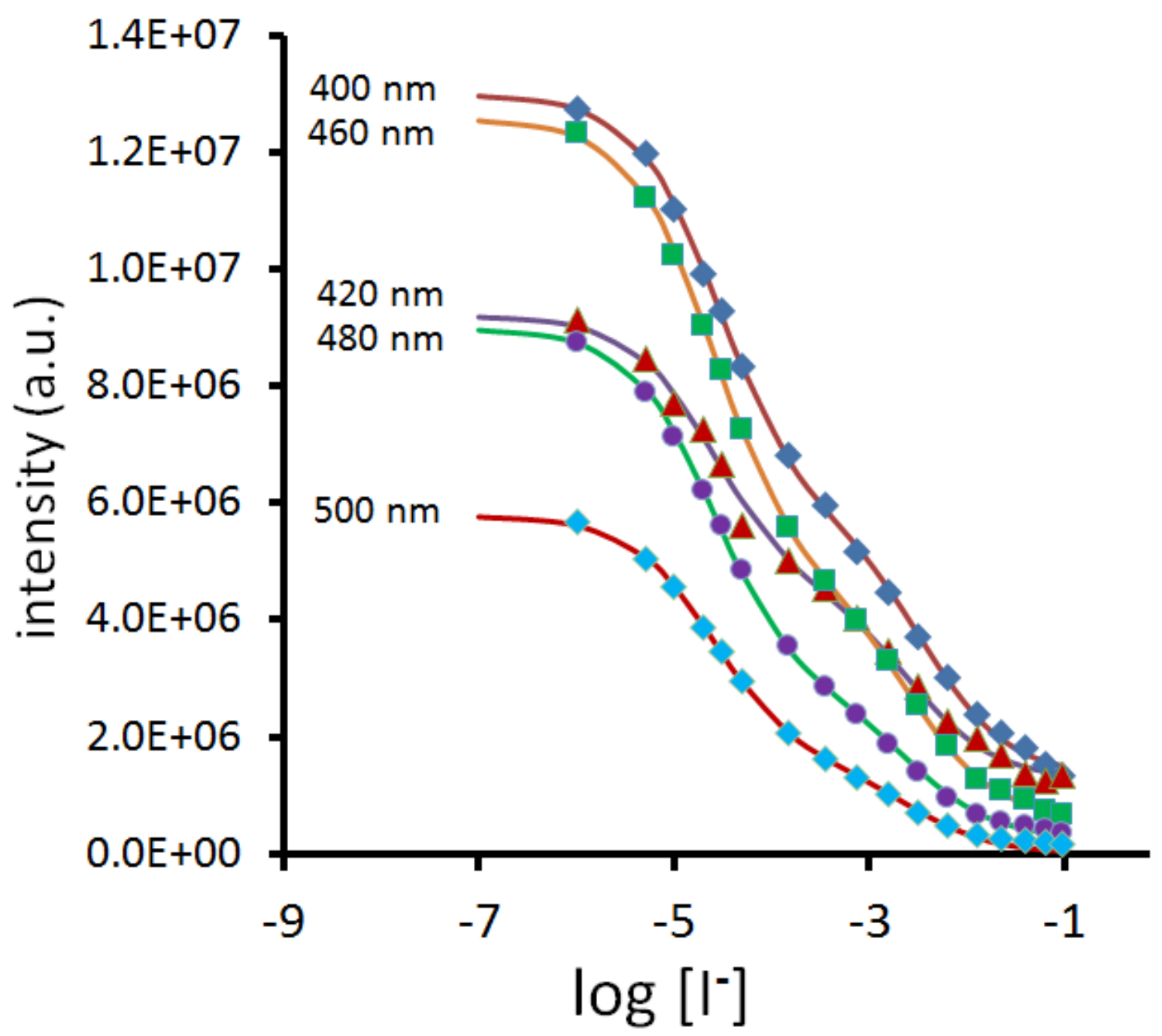

Figure 4. Variation of the fluorescence intensity of the $5 \times 10^{-6} \mathrm{M} \mathrm{Cd}^{\mathrm{II}}$ (adpa) complex in $50 \%$ $\mathrm{MeOH} / \mathrm{H}_{2} \mathrm{O}$ at $25^{\circ} \mathrm{C}$ as a function of $\mathrm{NaI}$ concentration. The solid points are the experimental fluorescence values, while the solid lines are theoretical curves of fluorescence intensity versus iodide concentration calculated using Solver [32] and $\log \mathrm{K}_{1}=4.56$ and $\log \mathrm{K}_{2}=2.51$ for binding of the $\mathrm{I}^{-}$to the $\mathrm{Cd}^{\mathrm{II}}(\mathrm{adpa})$ complex. Excitation wavelength $=350 \mathrm{~nm}$. 


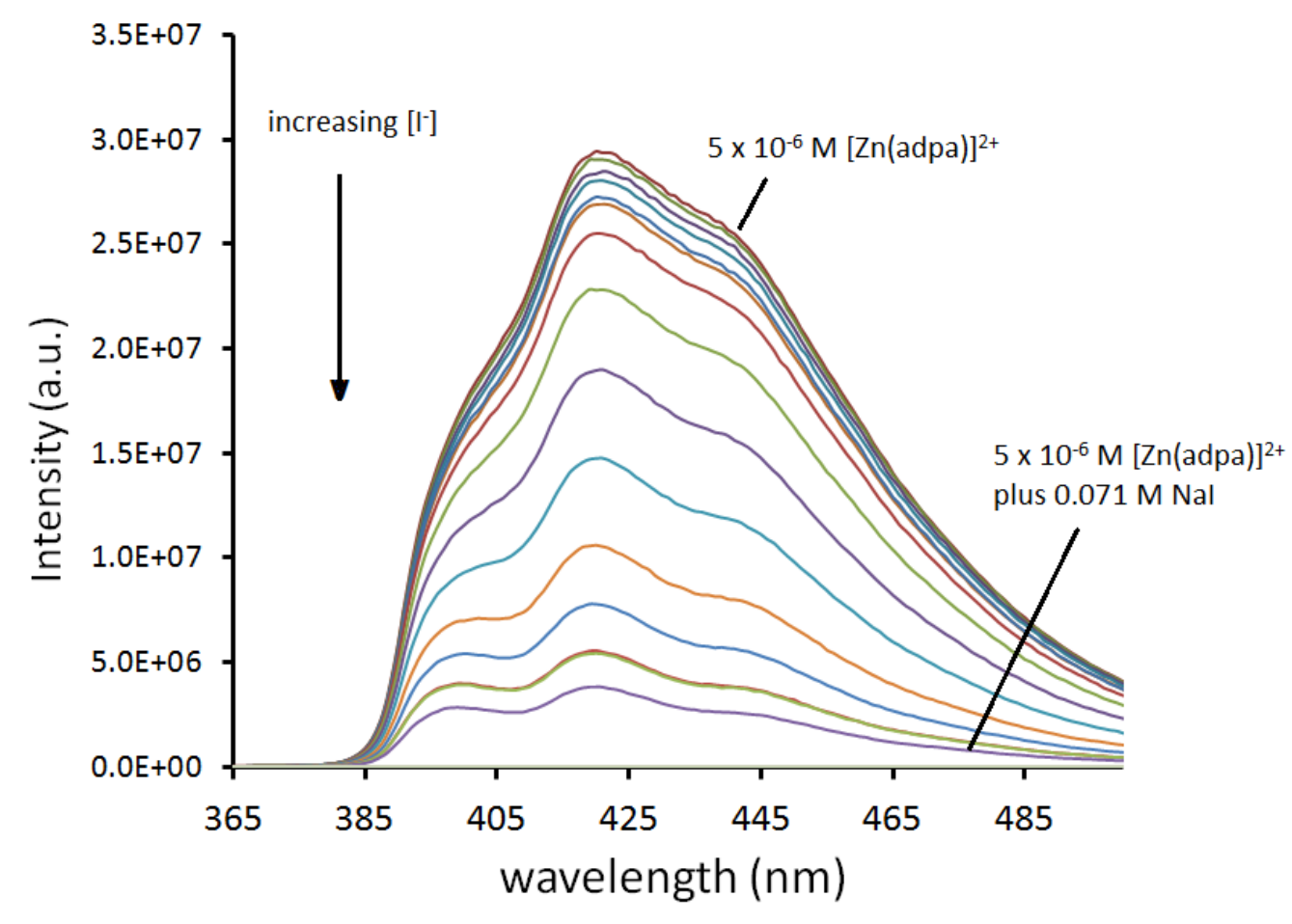

Figure 5. Effect of added $\mathrm{I}^{-}$on the fluorescence spectra of $5 \times 10^{-6} \mathrm{M} \mathrm{Zn}^{\mathrm{II}}$ (adpa) complex in $50 \%$ $\mathrm{MeOH} / \mathrm{H}_{2} \mathrm{O}$ at $\mathrm{pH} 6.43$ and $25^{\circ} \mathrm{C}$. Excitation wavelength $=350 \mathrm{~nm}$. 


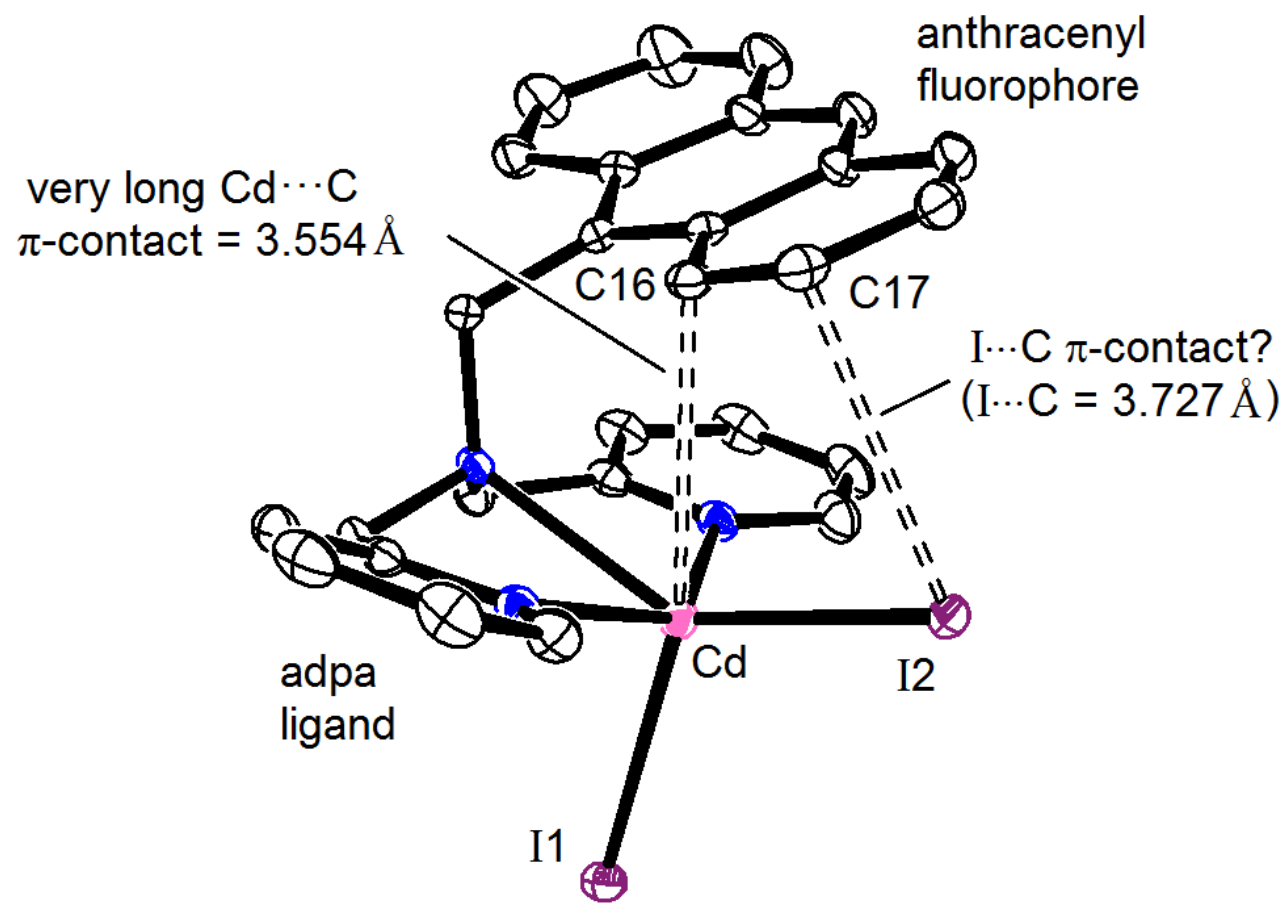

Figure 6. Structure of $\left[\mathrm{Cd}(\mathrm{adpa}) \mathrm{I}_{2}\right]$ (1) showing the very long $\mathrm{Cd} \cdots \mathrm{C} \pi$ contact, and the possible I $\cdots$ C $\pi$ contact to the fluorophore of adpa. Thermal ellipsoids are drawn at the $50 \%$ confidence level. Drawing made with ORTEP [33]. 


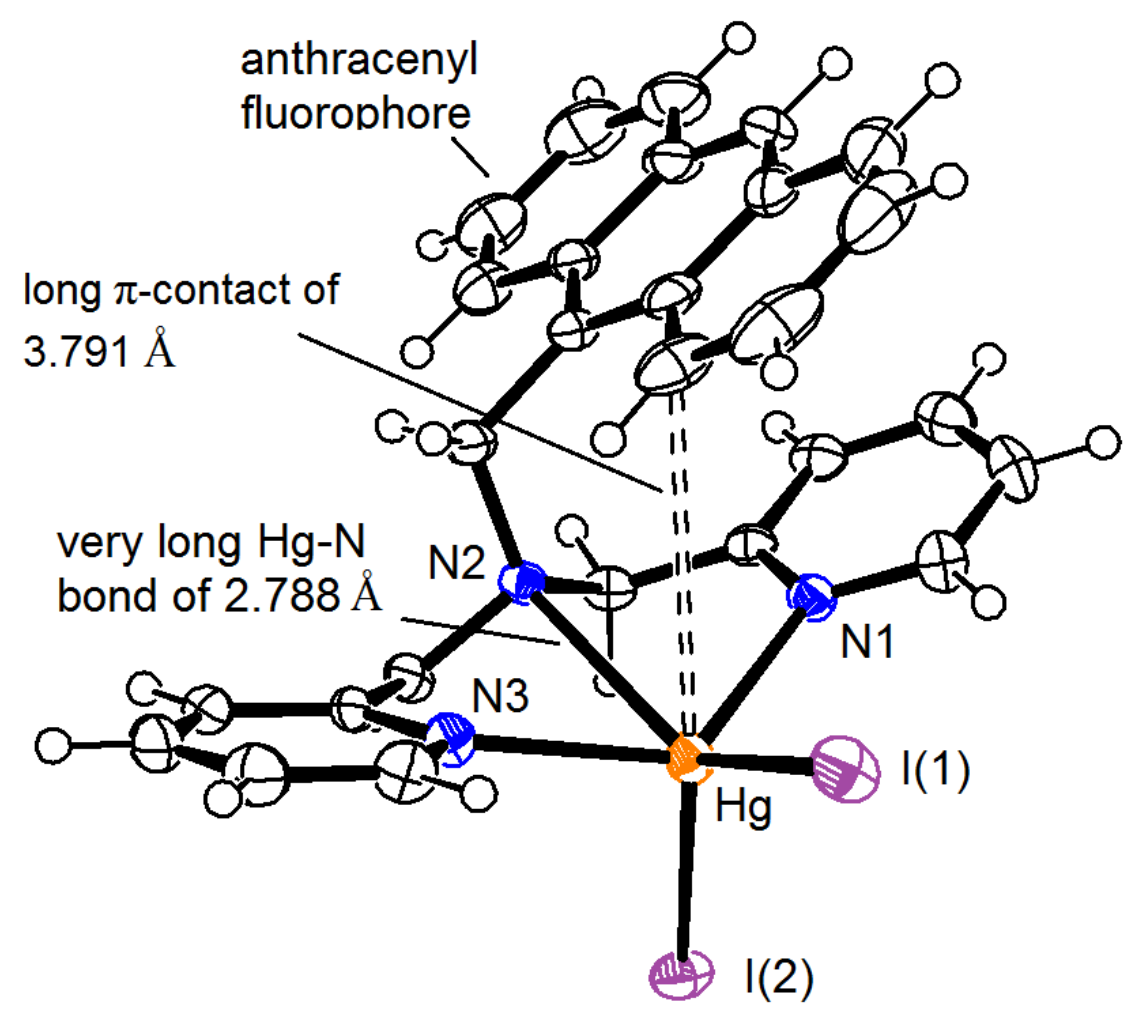

Figure 7. Structure of $\left[\mathrm{Hg}(\operatorname{adpa}) \mathrm{I}_{2}\right]$ (2) showing the very long $\mathrm{Hg}-\mathrm{N}$ bond to the saturated $\mathrm{N}$ donor of adpa $(\mathrm{N}(2))$, and the long $\mathrm{Hg} \cdots \mathrm{C} \pi$-contact to the fluorophore of adpa. Thermal ellipsoids drawn at the $50 \%$ confidence level. Drawing made with ORTEP [33]. 
Figure 8. Structure of the $\left[\mathrm{Zn}(\mathrm{adpa}) \mathrm{Cl}_{2}\right]$ complex (3), showing the lack of a $\pi$-contact between $\mathrm{Zn}^{\mathrm{II}}$ and the anthracenyl fuorophore. Thermal ellipsoids drawn at the $50 \%$ confidence level. Drawing made with ORTEP [33].

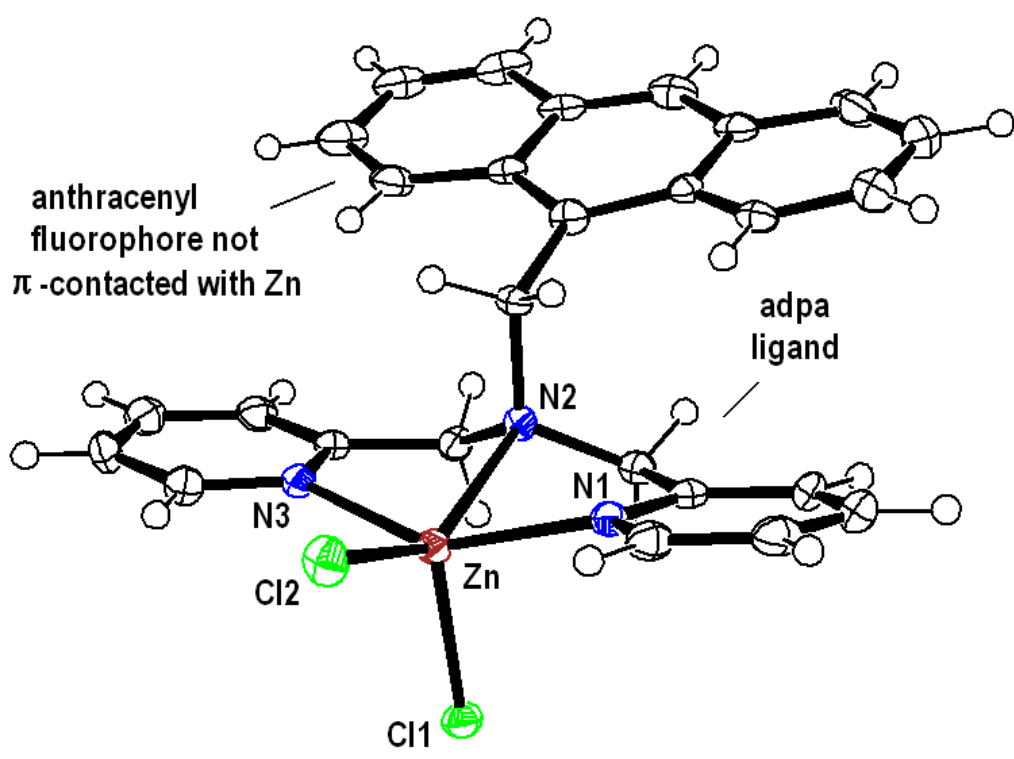




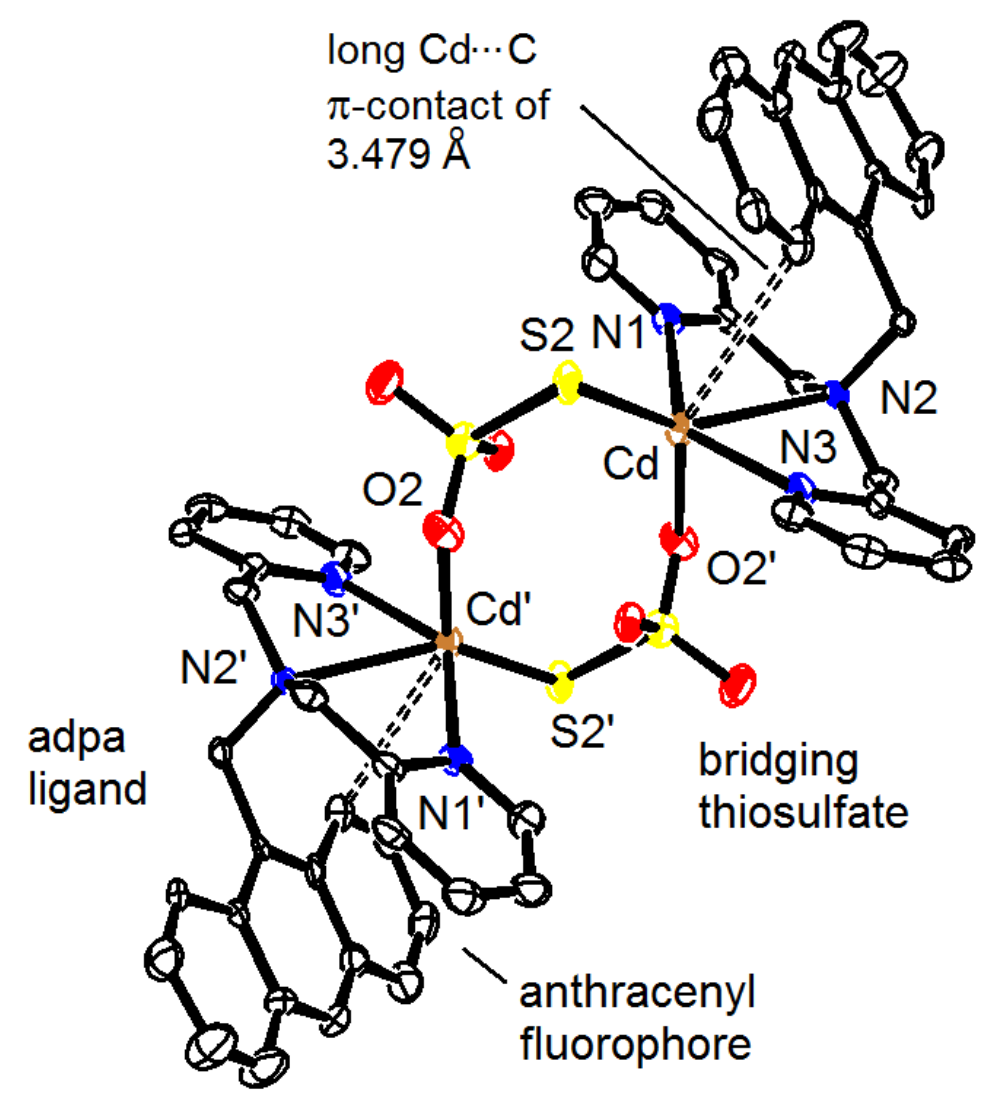

Figure 9. Structure of the thiosulfate bridged $\left[\mathrm{Cd}(\mathrm{adpa}) \mathrm{S}_{2} \mathrm{O}_{2}\right]_{2}$ complex dimer (4), showing the long $\pi$ contacts between $\mathrm{Cd}^{\mathrm{II}}$ ions and the anthracenyl fluorophores. Thermal ellipsoids drawn at the 50\% confidence level, $\mathrm{H}$ atoms omitted for clarity, and drawing made with ORTEP [33]. 


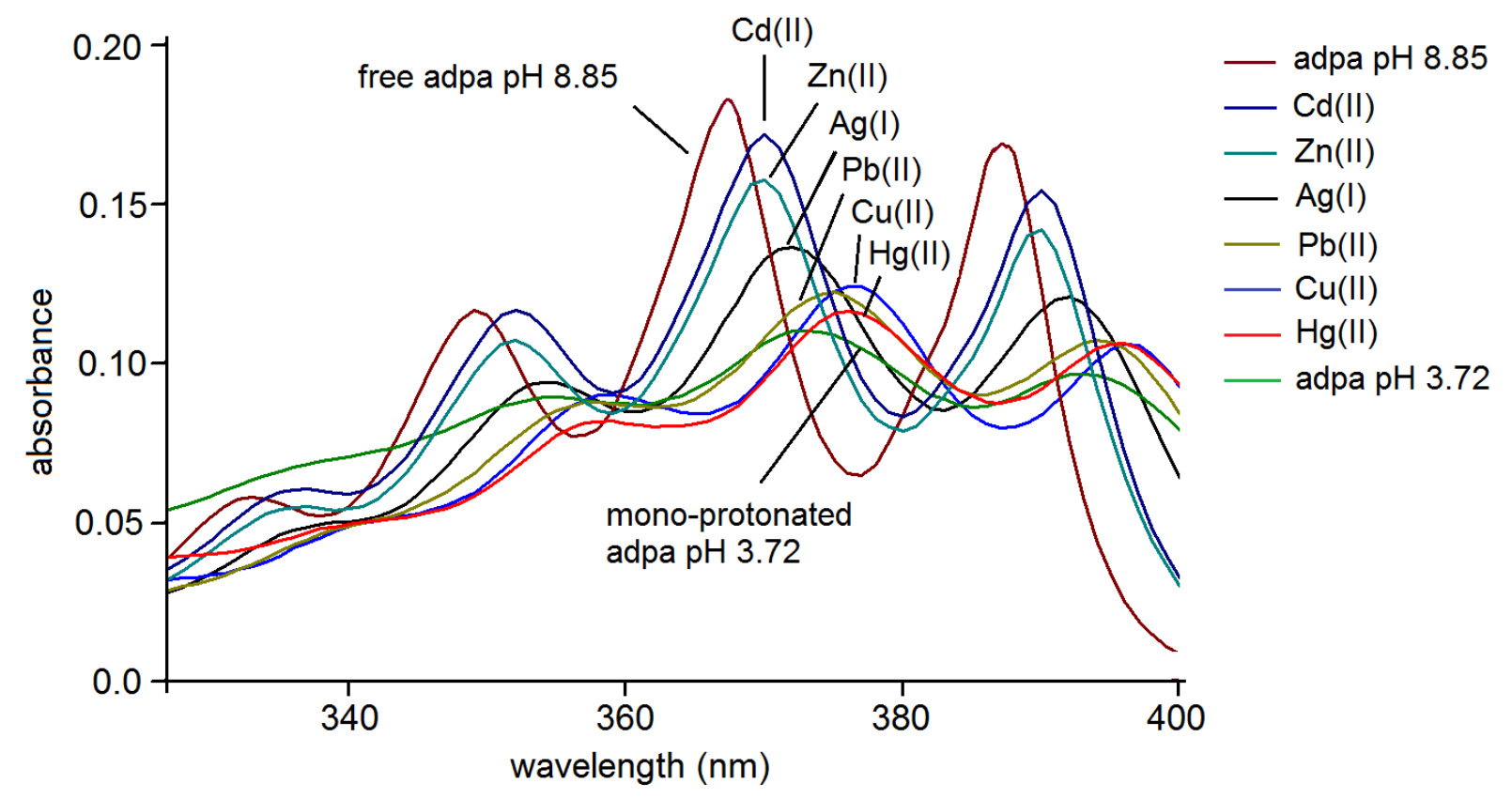

Figure 10. Absorbance spectra of adpa, and adpa complexes, $5 \times 10^{-5} \mathrm{M}$ adpa in $50 \%$ $\mathrm{MeOH} / \mathrm{H}_{2} \mathrm{O}$. These bands correspond to $\pi \rightarrow \pi^{*}$ transitions within the anthracenyl fluorophore. The spectra of the adpa complexes are the spectra obtained by titrating the adpa with metal ion solution until a limiting spectrum is obtained, which ensures complete formation of the 1:1 complex, which will not necessarily occur at a 1:1 metal:adpa ratio because of the low formation constants with adpa of most of the metal ions. 


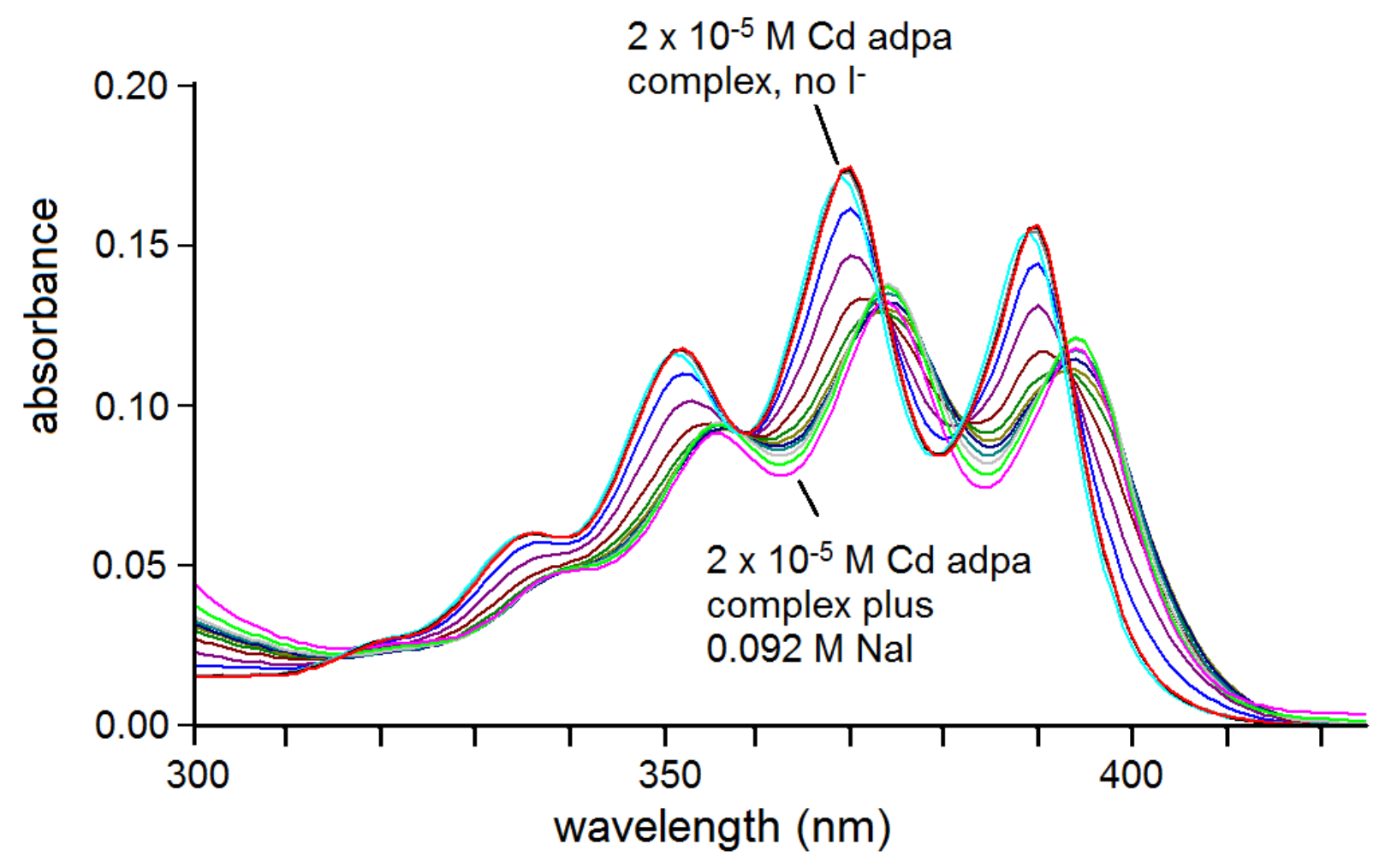

Figure 11. Absorbance spectra of the $\mathrm{Cd}^{\mathrm{II}}$ (adpa) complex, $5 \times 10^{-5} \mathrm{M}$ in $50 \% \mathrm{MeOH} / \mathrm{H}_{2} \mathrm{O}$ at $\mathrm{pH}$ 6.27 over a range of iodide concentrations. These bands correspond to $\pi \rightarrow \pi^{*}$ transitions within the anthracenyl fluorophore. 


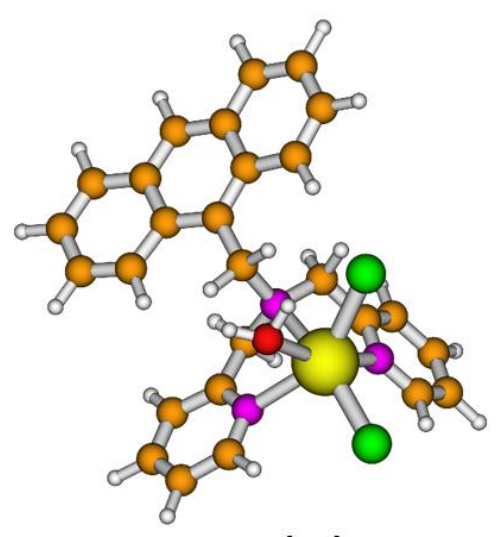

(a)

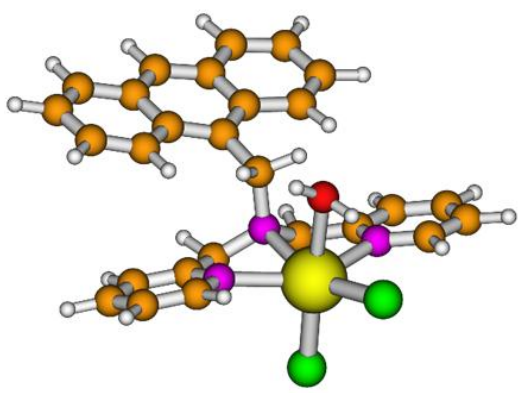

(b)

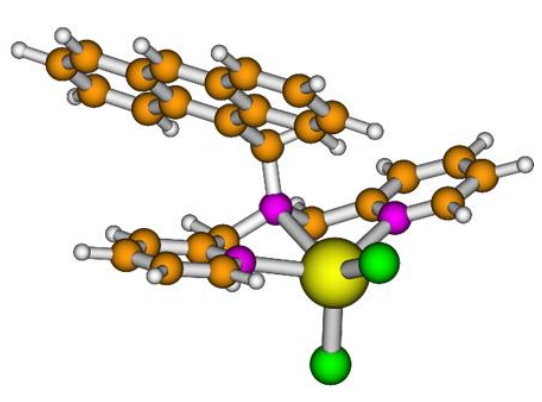

(c)

Figure 12. DFT optimized ground state structures of the $\mathrm{Cd}^{\mathrm{II}}(\mathrm{adpa}) \mathrm{Cl}_{2}$ complex. (a) The most stable structure with two pyridyl groups twisted (b) Two pyridyl groups are roughly on the same plane, which resembles the X-ray structure of $\mathrm{Zn}^{\mathrm{II}}(\mathrm{adpa}) \mathrm{Cl}_{2}$ (c) $\pi$-contacted form of $\mathrm{Cd}^{\mathrm{II}}(\mathrm{adpa}) \mathrm{Cl}_{2}$. The non- $\pi$ contacted forms, (a) and (b), have additional water molecule coordinated to $\mathrm{Cd}^{\mathrm{II}}$. Color scheme: $\mathrm{Cd}=$ yellow, $\mathrm{Cl}=$ green, $\mathrm{O}=$ red, $\mathrm{C}=$ orange, $\mathrm{N}=$ purple, $\mathrm{H}=$ gray. 

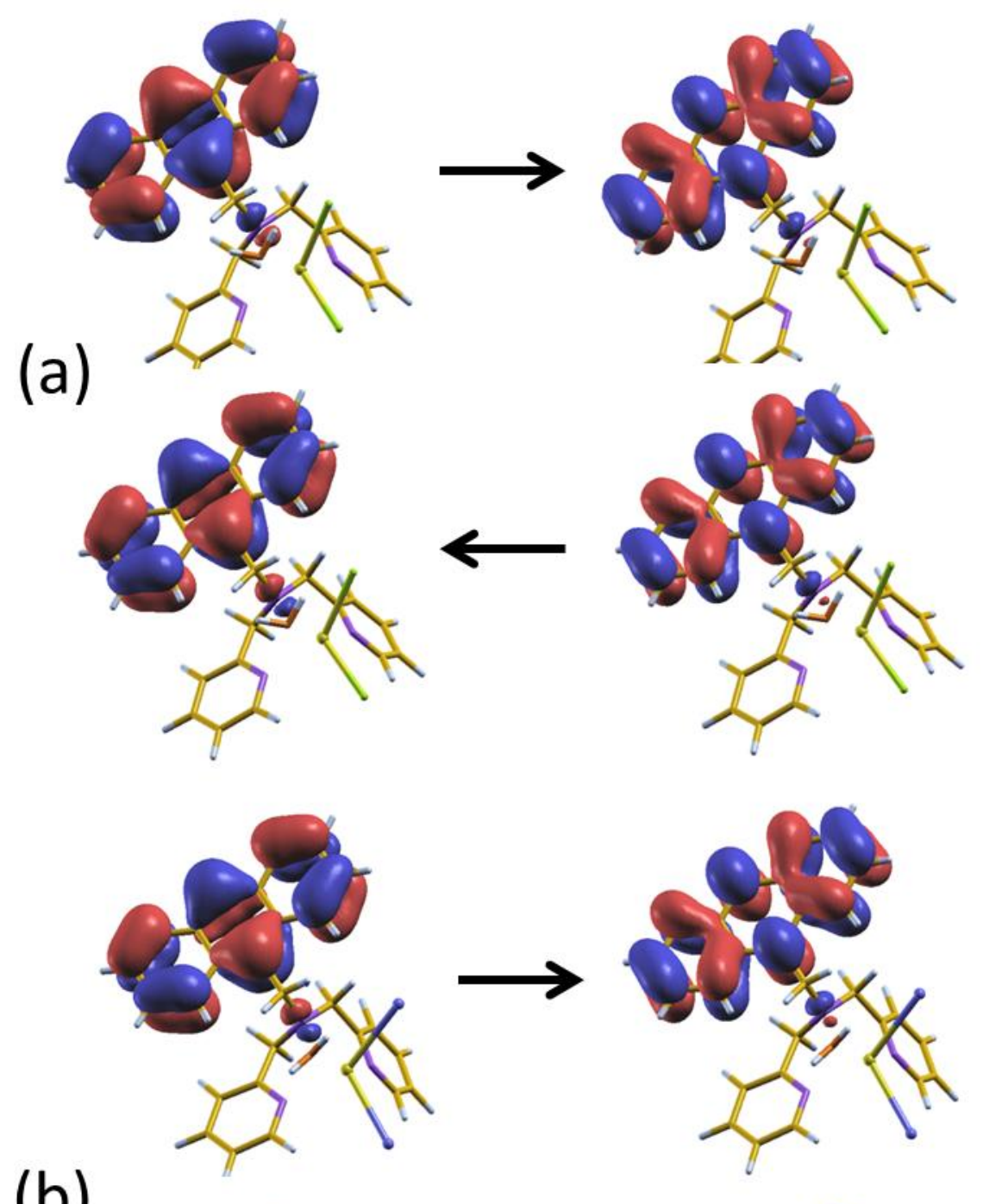

(b)

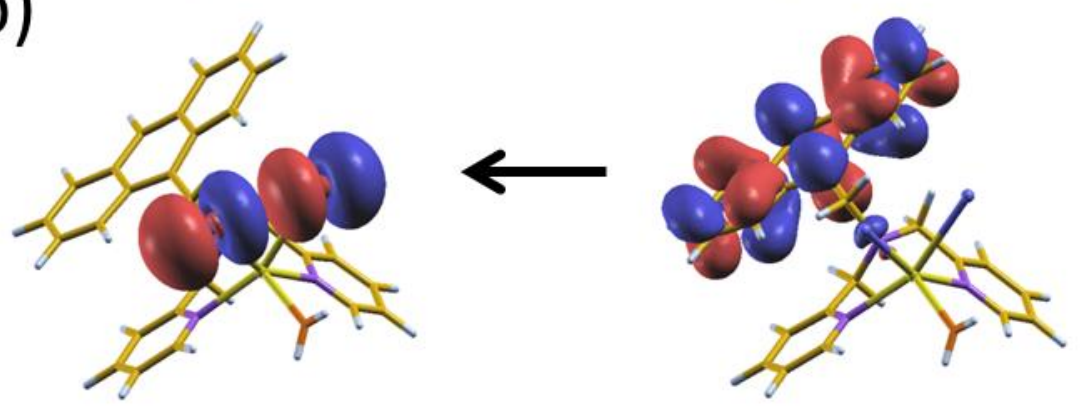

Figure 13. (a) The main contribution to the $S_{0} \rightarrow S_{1}$ (first row) and $S_{1} \rightarrow S_{0}$ (second row) transitions for the non- $\pi$-contacted $\mathrm{Cd}^{\mathrm{II}}(\mathrm{adpa}) \mathrm{Cl}_{2}\left(\mathrm{H}_{2} \mathrm{O}\right)$ complex. (b) The same transitions for the non- $\pi$-contacted $\mathrm{Cd}^{\mathrm{II}}(\operatorname{adpa}) \mathrm{I}_{2}\left(\mathrm{H}_{2} \mathrm{O}\right)$ complex. Notice the difference in structures between the ground and excited states of $\mathrm{Cd}^{\mathrm{II}}($ adpa $) \mathrm{I}_{2}\left(\mathrm{H}_{2} \mathrm{O}\right)$ complex. 